\title{
International Union of Basic and Clinical Pharmacology. LXXXV: Calcium-Activated Chloride Channels
}

\author{
Fen Huang, Xiuming Wong, and Lily Y. Jan \\ Department of Physiology, Howard Hughes Medical Institute, University of California, San Francisco, California
}

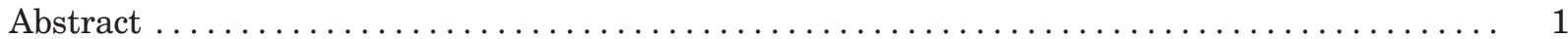

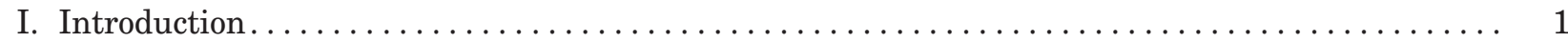

II. The discovery of the molecular identity for calcium-activated chloride channels $\ldots \ldots \ldots \ldots$

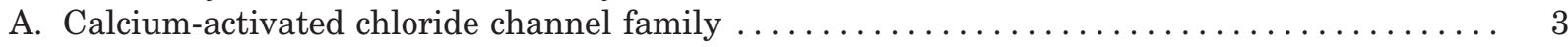

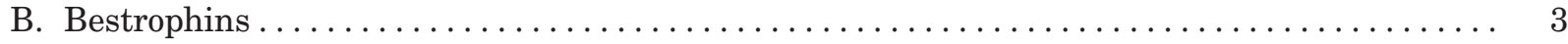

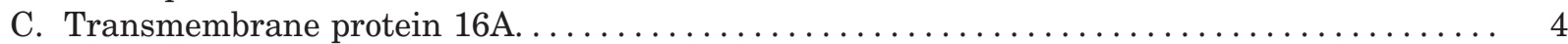

III. Expression and physiological function of transmembrane protein $16 \mathrm{~A} \ldots \ldots \ldots 4$

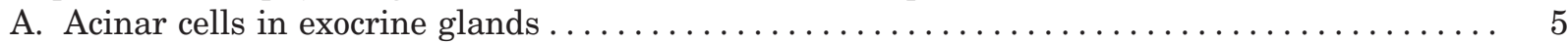

B. Epithelial cells in lung and gastrointestinal tract $\ldots \ldots \ldots \ldots \ldots$

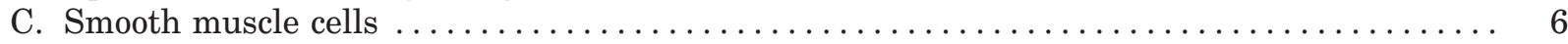

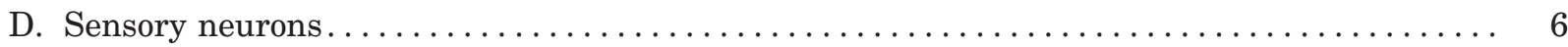

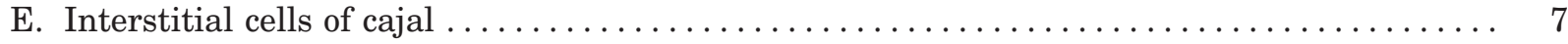

IV. Transmembrane protein $16 \mathrm{~A}$ structure and Function $\ldots \ldots \ldots \ldots \ldots$

A. The topology of transmembrane protein $16 \mathrm{~A} \ldots \ldots \ldots \ldots \ldots \ldots \ldots$

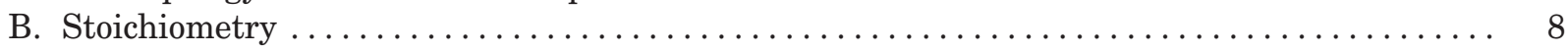

C. Biophysical properties of transmembrane protein $16 \mathrm{~A} \ldots \ldots \ldots \ldots$

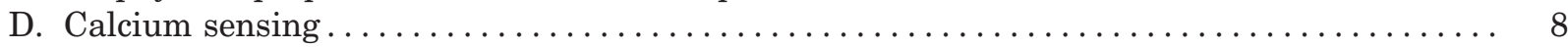

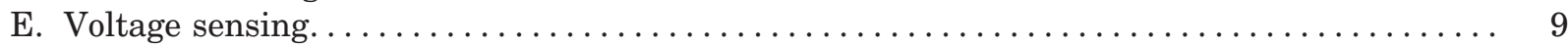

F. Molecular determinants of ion permeation/permeability $\ldots \ldots \ldots \ldots$

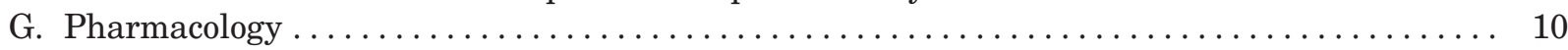

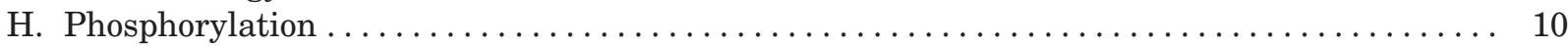

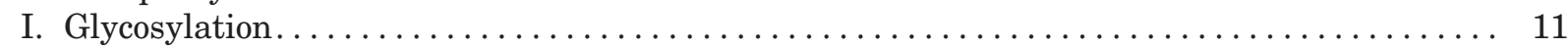

V. Transmembrane protein $16 \mathrm{~A}$ family members and disease correlations ............. 11

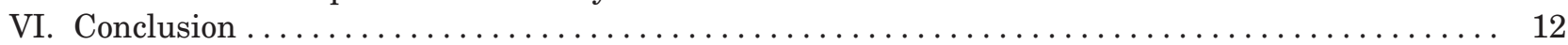

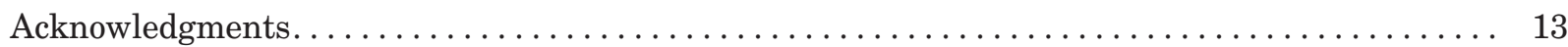

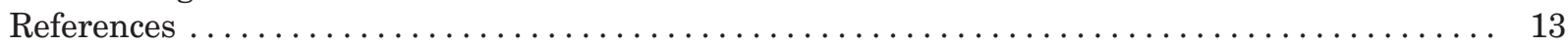

\begin{abstract}
Calcium-activated chloride channels (CaCCs) are widely expressed in various tissues and implicated in physiological processes such as sensory transduction, epithelial secretion, and smooth muscle contraction. Transmembrane proteins with unknown function 16 (TMEM16A) has recently been identified as

a major component of CaCCs. Detailed molecular analysis of TMEM16A will be needed to understand its structure-function relationships. The role this channel plays in physiological systems remains to be established and is currently a subject of intense investigation.
\end{abstract}

\section{Introduction}

Chloride $\left(\mathrm{Cl}^{-}\right)$, as the most abundant permeable anion in cells, plays an important role in a variety of cellular

Address correspondence to: Lily Y Jan, Howard Hughes Medical Institute, University of California, San Francisco, Mission Bay Campus, Rock Hall, 1550 4th Street, Room RH484, San Francisco, CA 94158-2811. Email: lily.jan@ucsf.edu 
ride channels can be grouped into four categories: ligand-gated chloride channels, voltage-activated chloride channels, cAMP-regulated chloride channels, and calcium-activated chloride channels $\left(\mathrm{CaCCs}^{1}\right)$ (Jentsch et al., 2002). The first three types of chloride channels have well established molecular identities and have been studied extensively in terms of protein structure and function and their involvement in diseases. CaCCs, however, have remained elusive for decades, although the existence of the $\mathrm{CaCC}$ currents has been well known since the 1980s (Eggermont, 2004; Hartzell et al., 2005; Planells-Cases and Jentsch, 2009; Duran et al., 2010).

With an ancestry preceding the conquest of land, CaCCs probably correspond to an ancient and evolutionarily conserved form of channels that are responsible for the action potential generation in the green algae of

\footnotetext{
${ }^{1}$ Abbreviations: ASL, airway surface liquid; Best, bestrophin; BK, large-conductance potassium channel; $\mathrm{CaCC}$, calcium-activated chloride channel/current; $\mathrm{CaMKII}, \mathrm{Ca}^{2+} /$ calmodulin-dependent kinase II; CFTR, cystic fibrosis transmembrane conductance regulator; CLCA, calcium-activated chloride channel family; DRG, dorsal root ganglia; DUF, domain of unknown function; GIST, gastrointestinal stromal tumor; HEK, human embryonic kidney; ICC, interstitial cell of Cajal; KN93, 2-(N-[2-hydroxyethyl])- $N$-(4-methoxybenzenesulfonyl)amino- $N$ (4-chlorocinnamyl)- $N$-methylamine; NFA, niflumic acid; PtdSer, phosphatidylserine; siRNA, small interfering RNA; STIC, spontaneous transient inward current; TM, transmembrane; TMEM16, transmembrane protein with unknown function 16 .
}

genera Chara and Nitella and the touch-sensitive plant Mimosa pudica (Berecki et al., 1999; Fromm and Lautner, 2007). In the animal kingdom, calcium-activated chloride currents were first noted in 1981, when injection of $\mathrm{Ca}^{2+}$ or $\mathrm{Ca}^{2+}$ ionophore into Rana pipiens eggs was observed to initiate a transient shift to positive membrane potentials in a $\mathrm{Cl}^{-}$-dependent manner (Cross, 1981; Schlichter and Elinson, 1981). CaCCs were then described in photoreceptors in salamander retina (Bader et al., 1982). Later studies in Xenopus laevis oocytes further characterized this calcium-activated chloride current (Barish, 1983; Miledi and Parker, 1984). Calcium-activated chloride current was subsequently recorded in rat lacrimal gland cells (Evans and Marty, 1986), cultured sensory neurons from rat dorsal root ganglion (Mayer, 1985), solitary cones from lizard retina (Maricq and Korenbrot, 1988), cultured AtT-20 pituitary cells (Korn and Weight, 1987), frog olfactory cilia (Kleene and Gesteland, 1991), guinea pig hepatocytes (Koumi et al., 1994), airway epithelial cells (Anderson and Welsh, 1991), and smooth muscle cells from portal vein and trachea (Pacaud et al., 1989; Janssen and Sims, 1992). Figure 1 illustrates the typical CaCC recorded from $X$. laevis oocytes and mammalian cells.

The wide expression of $\mathrm{CaCCs}$ in a variety of cells suggests their involvement in multiple physiological

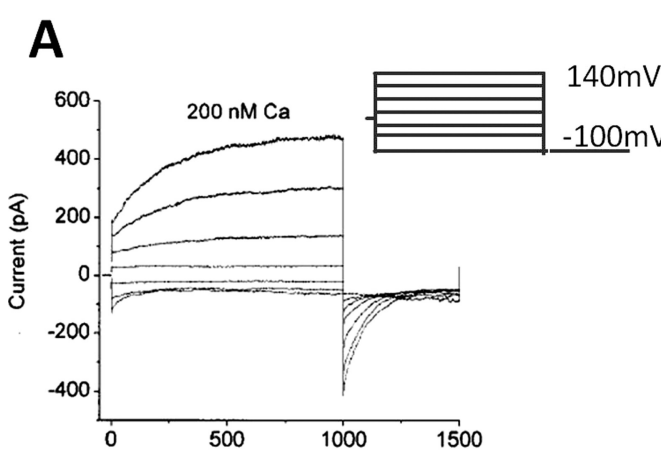

B
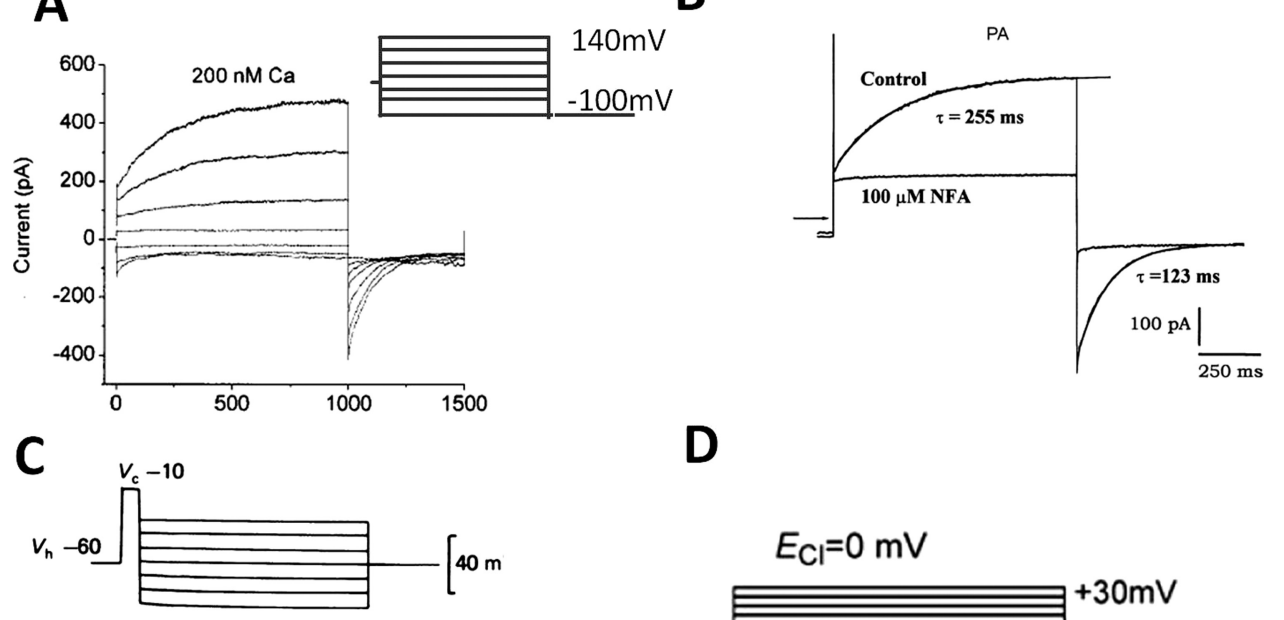

D
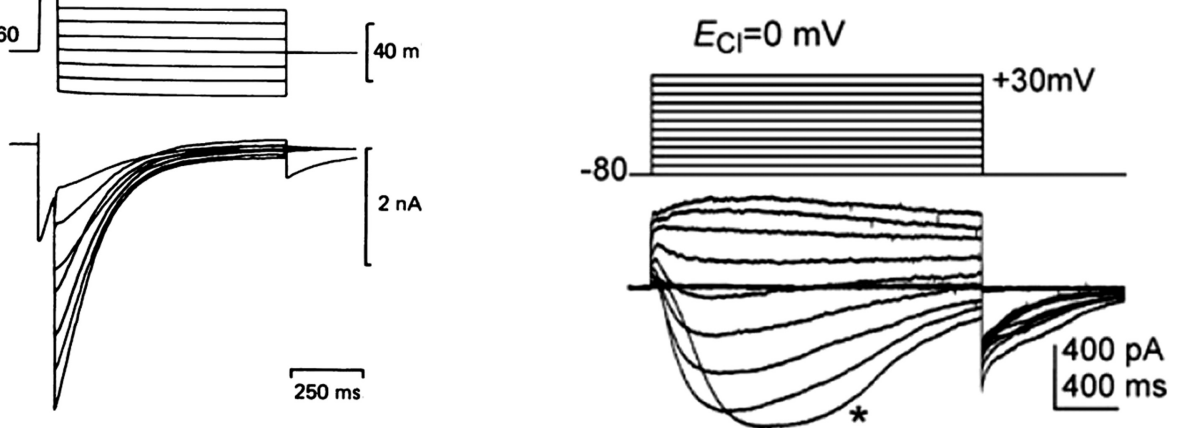

FIG 1. Examples of classic CaCCs recorded in X. laevis oocytes and mammalian cells. A, CaCC in X. laevis oocyte. The patches were clamped from a holding potential of $0 \mathrm{mV}$ to potentials between 140 and $-100 \mathrm{mV}$ for $1 \mathrm{~s}$, followed by a $500-\mathrm{ms}$ pulse to $-100 \mathrm{mV}(\mathrm{Qu}$ and $\mathrm{Hartzell}, 2000)$. B, CaCC recorded in rat pulmonary artery (PA) smooth muscle cells, representative current tracings recorded in the absence (Control) and presence of $100 \mu \mathrm{M}$ NFA, voltage-dependent currents were evoked by 1-s step depolarization from a holding potential of $-50 \mathrm{mV}$ to $+70 \mathrm{mV}$, followed by 1 -s return steps to $-80 \mathrm{mV}$ (Greenwood et al., 2001). C, CaCC recorded in cultured rat dorsal root ganglia neurons activated by a depolarizing prepulse (Mayer, 1985). $\mathrm{D}$, CaCC recorded in ICCs. ICCs were depolarized from -80 to $+30 \mathrm{mV}$ in $10-\mathrm{mV}$ increments from a holding potential of $-80 \mathrm{mV}$, and $\mathrm{ECl}^{-}$was adjusted to $0 \mathrm{mV}$ (Zhu et al., 2009). 
functions. In $X$. laevis oocytes, CaCC-mediated membrane depolarization prevents multiple sperm entry (Cross and Elinson, 1980). In epithelial cells, CaCCs are implicated in fluid secretion. CaCCs may also regulate contraction in smooth muscle cells as well as neuronal excitability in sensory neurons (Mayer, 1985; Maricq and Korenbrot, 1988; Kleene and Gesteland, 1991).

Biophysical hallmarks of CaCCs include the following:

- They are activated by cytosolic $\mathrm{Ca}^{2+}$ with half-maximal concentrations for activation in the submicromolar range, but the exact value varies with specific cell type, possibly due to differences in molecular composition or local cellular enviroment;

- They exhibit outward rectification at low intracellular $\mathrm{Ca}^{2+}$ but display a linear current-voltage relationship at higher intracellular $\mathrm{Ca}^{2+}$ concentrations; and

- The channels preferentially permeate large anions, the ionic selectivity being $\mathrm{NO}^{3-}>\mathrm{I}^{-}>\mathrm{Br}^{-}>\mathrm{Cl}^{-}>$ $\mathrm{F}^{-}$(Large and Wang, 1996; $\mathrm{Qu}$ and Hartzell, 2000).

It is important to keep in mind that calcium-activated chloride currents in different cells may be generated by more than one type of channel protein. Indeed, differences have been noted in terms of single channel conductance, channel activation and deactivation kinetics, kinase-dependence of channel activity, and pharmacological sensitivity to traditional $\mathrm{Cl}^{-}$channel blockers (Eggermont, 2004; Planells-Cases and Jentsch, 2009).

\section{The Discovery of the Molecular Identity for Calcium-Activated Chloride Channels}

Despite extensive biophysical and physiological studies of calcium-activated chloride currents, lifting the veil on its molecular identity turned out to be a long and tortuous process. There were two main obstacles. First, expression cloning methods were hampered because of endogenous expression of $\mathrm{CaCCs}$ in the traditional $X$. laevis oocyte expression system; second, blockers specific for CaCCs (over other chloride channels) were not available. Nevertheless, efforts to identify the channel went on, and several protein families were cloned and proposed as candidates for the $\mathrm{CaCC}$, but they all failed to recapitulate properties characteristic of endogenous CaCCs. Here we give a brief review of the efforts behind the discovery of the channel and then focus on the most recently cloned candidates for the traditional $\mathrm{CaCC}-$ members of the transmembrane protein with unknown function 16A (TMEM16) family.

\section{A. Calcium-Activated Chloride Channel Family}

An early candidate for CaCC is CLCA, which was purified from bovine trachea and named after a calciumdependent chloride conductance found in trachea and in other secretory epithelial tissues (Cunningham et al., 1995; Agnel et al., 1999; Komiya et al., 1999). Notwith- standing the nomenclature, we now know that CLCA is unlikely to function as a calcium-activated chloride channel. Electrophysiological characterization of bovine CLCA expressed in X. laevis oocytes, and COS-7 cells has been reported (Cunningham et al., 1995). Although CLCA currents were similar to CaCCs in terms of anionic selectivity, there are major discrepancies. First, the CLCA currents recorded in oocytes could be activated solely by depolarization in the absence of $\mathrm{Ca}^{2+}$ increase. Second, currents were not blocked by niflumic acid (NFA), which had been shown to effectively block endogenous CaCCs. Third, the current-voltage relationship of whole-cell currents recorded in COS-7 cells was linear instead of outwardly rectifying. Finally, CLCA current was sensitive to the reducing agent dithiothreitol, while endogenous $\mathrm{CaCCs}$ are not (Cunningham et al, 1995). Family members related to bovine CLCA were subsequently cloned, including two bovine [bCLC1, bCLCA2 (Lu-ECAM-1)], three mouse (mCLCA1, mCLCA2, mCLCA3), and four human (hCLCA1, hCLCA2, hCLCA3, hCLCA4) homologs (Pauli et al., 2000; Loewen and Forsyth, 2005). Among them, hCLCA1, mCLCA3, and pCLCA1 have a similar distribution pattern in the three species, with high expression in mucus-producing epithelia in the gastrointestinal and respiratory tracts. Overexpression of hCLCA1 or mCLCA3 has been linked to mucus overexpression in cystic fibrosis and asthma (Nakanishi et al., 2001; Zhou et al., 2001; Toda et al., 2002; Erle and Zhen, 2006). However, biochemical studies have shown that hCLCA1 and mCLCA3 are secreted nonintegral membrane proteins and are therefore not ion channels (Gibson et al., 2005). A metallohydrolase structural domain was predicted from analysis of the CLCA protein sequences, which raises the possibility that CLCA can perform catalytic functions similar to those of metalloproteases (Pawłowski et al., 2006).

Several reviews have thorough discussions of the strucure and function of CLCA family members and a detailed comparison of CLCA properties with endogenous CaCCs (Eggermont, 2004; Loewen and Forsyth, 2005; Patel et al., 2009). Given the available data on the expression pattern, biophysical and biochemical properties of CLCA, it seems reasonable to conclude that CLCA is not a valid candidate for $\mathrm{CaCC}$. Further study will be needed to elucidate the function of CLCA.

\section{B. Bestrophins}

Bestrophin was first discovered as the gene responsible for Best vitelliform macular dystrophy (VMD2) (Petrukhin et al., 1998) and was shown to produce a $\mathrm{Cl}^{-}$ conductance when heterologously expressed in HEK293 cells (Sun et al., 2002; Tsunenari et al., 2003). Mutagenesis studies have been performed to establish a direct link between protein and current (Qu et al., 2004). Bestrophins seem to be genuine anion channels that are activated by physiological levels of calcium; thus, they have been tentatively proposed to be CaCCs. However, 
the biophysical properties of these channels measured by recording from both whole-cell patch-clamp and excised giant membrane patches did not reproduce all the hallmarks of classic CaCCs as recorded in $X$. laevis oocytes. In particular, classic $\mathrm{CaCCs}$ exhibit voltagedependent kinetics and outward rectification that is not seen with wild-type human bestrophin-1 (Best1) or mouse Best2 (Tsunenari et al., 2003; Qu et al., 2004; Tsunenari et al., 2006; Hartzell et al., 2008). Furthermore, $\mathrm{Ca}^{2+}$-activated $\mathrm{Cl}^{-}$currents in olfactory sensory neurons and submandibular salivary gland acinar cells were unaffected in Best2 knockout mice (Pifferi et al., 2009b; Romanenko et al., 2010). Studies with Best2 knockout mice revealed that Best2 is a $\mathrm{HCO}^{3-}$ channel that localizes to the basolateral membrane of mucinsecreting colonic goblet cells and not the apical membrane of $\mathrm{Cl}^{-}$-secreting enterocytes in mouse colon (Yu et al., 2010). Knock-in mice carrying the Best vitelliform macular dystrophy-causing mutation W93C in Best1 recapitulate the retinal pathology seen in human patients. However, retinal pigment epithelial cells from Best ${ }^{\mathrm{W} 93 \mathrm{C}}$ mice exhibited normal CaCC conductances (Zhang et al., 2010). Best3 is essential for the cGMP-dependent calcium-activated chloride conductance in vascular smooth muscle cells, as shown by siRNA knockdown experiments. However the classic $\mathrm{CaCC}$ was not affected by Best3 downregulation (Matchkov et al., 2008). In summary, evidence shows that bestrophins can function as anion channels but probably not as the classic CaCC.

\section{Transmembrane Protein 16A}

Enigmatic for nearly 20 years, the molecular identity of CaCCs finally came to light in 2008, from the work of not just one but three laboratories simultaneously. These laboratories from three continents took different approaches but all reported the same molecule, TMEM16A, as a bona fide CaCC (Caputo et al., 2008; Schroeder et al., 2008; Yang et al., 2008). As mentioned previously, $X$. laevis oocytes used in traditional expression cloning approaches express endogenous CaCCs and are therefore inadequate as an expression system for CaCC cloning. Schroeder et al. (2008) realized that a different amphibian, the Axolotl salamander (Ambystoma mexicanum), is physiologically polyspermic and found that their oocytes are devoid of CaCC activity. This paved the way for an expression cloning approach using Axolotl oocytes as the expression system and $X$. laevis oocytes as the source for CaCC transcripts, leading to the identification of TMEM16A as a subunit of the channel responsible for CaCCs. Yang et al. (2008) pinned down TMEM16A from a bioinformatic screen for novel membrane proteins with more than two transmembrane domains. Caputo et al. (2008) recognized that CaCCs are up-regulated in interleukin-4-treated human bronchial epithelial cells and identified TMEM16A from a microarray of global gene expression analysis. TMEM16A was then verified to be a CaCC by siRNA gene-silencing experiments and heterologous expression. In all three studies, heterologous expression of TMEM16A in different cell types generated $\mathrm{Cl}^{-}$currents with the classic properties of CaCCs. TMEM16A belongs to the family of "Transmembrane proteins with unknown function 16," abbreviated as TMEM16, which includes nine other family members. TMEM16A is also known as anoctamin 1 (abbreviated ANO1), nomenclature that incorporates the concepts that TMEM16 family members are anion channels and have eight putative transmembrane segments (Yang et al., 2008). In this review, we retain the TMEM16 nomenclature, because it is still premature to assume that all TMEM16 family members are anion channels, and there are other concerns about the ANO nomenclature raised in another review (Flores et al., 2009).

TMEM16B, another member of the TMEM16 family, has also been shown to give rise to CaCCs when heterologously expressed, but with faster activation kinetics, less calcium sensitivity, and smaller single unit conductance compared withTMEM16A (Pifferi et al., 2009a; Stephan et al., 2009; Stöhr et al., 2009). The measured electrophysiological properties of TMEM16B in the whole-cell configuration in HEK 293T cells are largely similar to the native olfactory CaCC (Sagheddu et al., 2010). Recent studies of TMEM16B knockout mice have confirmed that TMEM16B is responsible for CaCC in olfactory neurons (Billig et al., 2011).

\section{Expression and Physiological Function of Transmembrane Protein 16A}

Before the discovery of TMEM16A as a CaCC, it was in fact already known to oncologists by various namesdiscovered on gastrointestinal stromal tumors protein 1 (DOG-1), oral cancer overexpressed 2 (ORAOV2), and tumor-amplified and overexpressed sequence 2 (TAOS2)-because of its high expression levels in some tumors, including gastrointestinal stromal tumors (GIST) (West et al., 2004; Espinosa et al., 2008), oral and esophageal squamous cell carcinoma (Huang et al., 2006; Kashyap et al., 2009). It has been suggested to serve as a hallmark for GIST, although its function in tumor biology is unknown.

CaCC currents have been recorded in various cell types, and the physiological significance of the channel has been the object of much investigation and speculation (Hartzell et al., 2005). With TMEM16A as a newly discovered $\mathrm{CaCC}$, scientists are now trying to answer the following questions: Is the TMEM16 family responsible for the endogenous CaCC? How do they contribute to physiological processes? The knockout mouse for TMEM16A was generated after the observation of TMEM16A enrichment in the zone of polarizing activity at the distal limb, before molecular identification of TMEM16A as CaCC (Rock et al., 2008). These mice have been used to validate TMEM16A expression and func- 
tion by immunocytochemistry, biophysical and physiological studies (Flores et al., 2009; Galietta, 2009; Gomez-Pinilla et al., 2009; Gritli-Linde et al., 2009; Huang et al., 2009; Hwang et al., 2009; Rock et al., 2009).

\section{A. Acinar Cells in Exocrine Glands}

CaCCs recorded from acinar cells from lachrymal, airway submucosal, parotid, and submandibular glands, as well as from the pancreas, share properties similar to those of the $X$. laevis oocyte CaCCs (Evans and Marty, 1986; Smith and Gallacher, 1992; Ishikawa and Cook, 1993; Zhang and Roomans, 1999; Park et al., 2001; Lee and Foskett, 2010). The transepithelial movement of $\mathrm{Cl}^{-}$ is the primary driving force for fluid secretion by exocrine gland acinar cells and has been speculated to contribute to the zymogen exocytosis (Thévenod, 2002). Entry of $\mathrm{Cl}^{-}$across the basolateral membrane is mediated by a $\mathrm{Na}^{+} / \mathrm{K}^{+} / 2 \mathrm{Cl}^{-}$cotransporter and the paired $\mathrm{Na}^{+} / \mathrm{H}^{-}$ and $\mathrm{Cl}^{-} / \mathrm{HCO}^{3-}$ exchangers, whereas $\mathrm{Cl}^{-}$exits the apical membrane via CaCCs (Thévenod, 2002; Melvin et al., 2005).

Huang et al. (2009) raised an antibody specific for mouse TMEM16A as demonstrated by using the TMEM16A knockout mice as a negative control for immunocytochemistry. Robust TMEM16A expression is found in the apical membrane of acinar cells of salivary glands and the pancreas. Moreover, electrophysiological studies have shown that TMEM16A is a critical component of the acinar CaCCs and essential for saliva pro- duction by the submandibular gland (Yang et al., 2008; Romanenko et al., 2010) (Fig. 2A).

CaCCs have also been recorded in duct cells of salivary glands and the pancreas (al-Nakkash and Cotton, 1997; Zeng et al., 1997). However, TMEM16A expression could not be detected in the ductal cells by immunocytochemistry (Huang et al., 2009). It is possible that immunocytochemistry is not sensitive enough to detect low-level expression of TMEM16A. Alternatively, other channels may serve as CaCCs in those cells. TMEM16A expression has also been found in the porcine bronchial submucosal gland serous acinar cells, which may mediate the agonist-induced fluid secretion in those cells (Lee and Foskett, 2010).

\section{B. Epithelial Cells in Lung and Gastrointestinal Tract}

CaCCs in pulmonary and intestinal epithelial cells have attracted great interest because of the therapeutic potential in cystic fibrosis, which is caused by mutations in the gene encoding the cystic fibrosis transmembrane conductance regulator (CFTR), a cAMP-regulated chloride channel (Cuthbert, 2011). The presence of CaCCs in the apical membrane of airway epithelial cells is well documented, but it is still controversial in intestinal epithelia (Anderson and Welsh, 1991; Morris et al., 1992; Barrett and Keely, 2000).

Immunocytochemistry detects TMEM16A expression in the airway but not in the intestinal epithelia. Moreover, the expression of TMEM16A in airway epithelia is
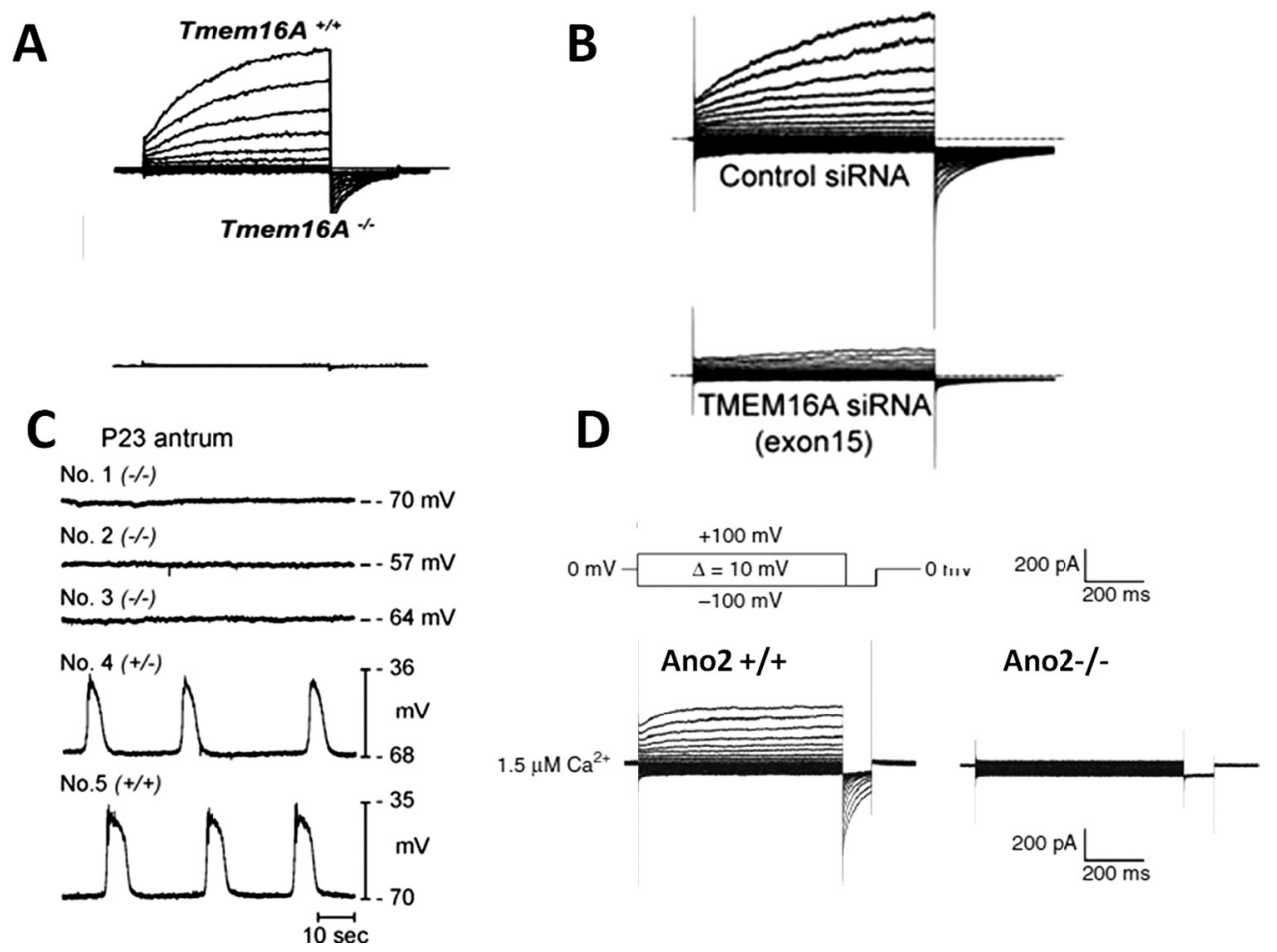

FIG. 2. Functional correlation between CaCC in native cells and TMEM16 family members. A, CaCC in submandibular salivary gland acinar cells

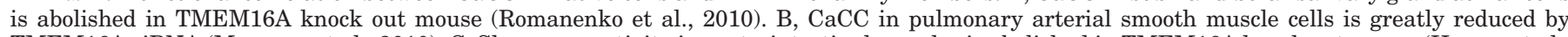

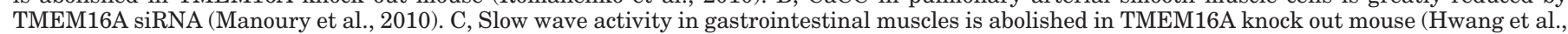
2009). D, CaCC is absent in the TMEM16B knockout mouse olfactory sensory neurons (Billig et al., 2011). 
much lower than in airway smooth muscle cells (Huang et al., 2009). Transepithelial short circuit recordings from tracheal epithelia of wild-type and TMEM16A knockout mice reveal that TMEM16A contributes little to the basal, unstimulated, $\mathrm{Cl}^{-}$secretion but accounts for approximately $60 \%$ of purinoceptor (UTP)-regulated CaCC activity (Rock et al., 2009).

The precise role of $\mathrm{CaCCs}$ in airway epithelia remains to be established. Both CFTR and CaCCs have been suggested to be important for electrolyte and fluid secretion for mucous hydration and protection against infection (Eggermont, 2004). It has been shown that the airway surface liquid (ASL) height under basal conditions is maintained by CFTR, whereas CaCCs do not seem to significantly affect the basal ASL height (Tarran et al., 2002). It will be interesting to investigate whether $\mathrm{CaCC}$ is important in acutely regulating ASL height in response to agonists such as nucleotides and histamines. Given that TMEM16A expression is up-regulated by cytokines in cultured airway epithelial cells, it may be particularly relevant to pulmonary diseases such as inflammation and asthma (Zhou et al., 2001; Caputo et al., 2008).

TMEM16A knockout mice exhibit significant neonatal lumenal mucus accumulation in the trachea, which could result from insufficient fluid secretion for mucus hydration. Developmental defects resulting in tracheomalacia could also impair mucus clearance (Rock et al., 2009). More studies will be needed to tease out the cause of the mucus accumulation in mice lacking TMEM16A.

\section{Smooth Muscle Cells}

CaCCs have been extensively studied in smooth muscle cells from a variety of tissues, including portal vein, trachea, lymphatic vessels and pulmonary artery (Pacaud et al., 1989; Large and Wang, 1996; ZhuGe et al., 1998; Sergeant et al., 2001; Angermann et al., 2006; von der Weid et al., 2008).

The expression of TMEM16A is detected by immunocytochemistry in smooth muscle cells in mouse airway and reproductive tracts, but not in the gastrointestinal tract (Huang et al., 2009). Reduction of TMEM16A expression with siRNAs in pulmonary artery smooth muscle cells led to an almost total loss of whole-cell $\mathrm{CaCC}$ currents (Manoury et al., 2010) (Fig. 2B). TMEM16A mRNA is also detected in smooth muscle cells isolated from mouse portal vein, thoracic aorta, and carotid artery with varied abundance (Davis et al., 2010). Further studies incorporating negative controls such as knockout mice or RNA interference knockdown will be needed to determine whether TMEM16A is critical for CaCC activity in those smooth muscle cells.

CaCCs in smooth muscle are expected to produce membrane depolarization and sustain contraction, especially in response to excitatory agonists. To date, the physiological function of endogenous CaCCs in smooth muscle cells has mostly been examined pharmacologi- cally. NFA reduces the amplitude and frequency of spontaneous contractions of smooth muscles cells from portal vein; thus, CaCCs may contribute to the inherent rhythmicity (Large and Wang, 1996; Saleh and Greenwood, 2005). Activation of muscarinic receptors in mammalian tracheal myocytes causes release of $\mathrm{Ca}^{2+}$ from intracellular stores and subsequent activation of $\mathrm{Cl}^{-}$conductance. However, this conductance does not seem to be required for contraction (Janssen and Sims, 1992). In addition, spontaneous depolarizations by $\mathrm{Ca}^{2+}$ sparks, which turn on $\mathrm{Ca}^{2+}$-activated $\mathrm{Cl}^{-}$channels to produce spontaneous transient inward currents (STICs), have been observed in smooth muscle cells in the absence of agonists, although whether and how STICs contribute to the smooth muscle cell contraction remains to be determined (Hogg et al., 1993; ZhuGe et al., 1998; Bao et al., 2008). It is worth noting that fetal mice deficient for TMEM16A lack the expected transverse orientation of the trachealis muscle, which is replaced by clusters of smooth muscle (Rock et al., 2008). Tracheomalacia in TMEM16A knockout mice could result from the abnormalities of smooth muscle activity during airway development. It will be interesting to investigate whether TMEM16A is responsible for STICs and how TMEM16A regulates the contraction of smooth muscle cells.

\section{Sensory Neurons}

Sensory neurons from rat dorsal root ganglia (DRG) are among the first mammalian cells in which $\mathrm{CaCCs}$ were recorded and characterized (Mayer, 1985). In quail trigeminal ganglia and DRG, CaCCs are developmentally regulated with a peak in expression during peripheral synaptogenesis (Bernheim et al., 1989). CaCCs persist in a subset of mouse normal sympathetic ganglion neurons, which can be recorded directly from acutely dissected ganglia (De Castro et al., 1997). Axotomy induces up-regulation of CaCCs in DRG, sympathetic and nodose ganglion neurons (Sánchez-Vives and Gallego, 1994; Lancaster et al., 2002; André et al., 2003; AlJumaily et al., 2007). In the normal mouse DRG, CaCCs are expressed selectively in a subset of medium diameter $(30-40 \mu \mathrm{m})$ sensory neurons. Sciatic nerve transection not only increases both $\mathrm{CaCC}$ amplitude and its expression in medium-diameter neurons but also induces $\mathrm{CaCC}$ expression in the large-diameter neurons (40-50 $\mu \mathrm{m})$, generally thought to be low-threshold skinand muscle-innervating neurons conveying touch and proprioceptive information (André et al., 2003).

Immunostaining signals for TMEM16A have been detected in most DRG sensory neurons, and small sensory neurons tend to stain more densely than large sensory neurons (Yang et al., 2008). At present, neither the functional relevance of this current in normal or injuryrelated processes nor its molecular nature is known. CaCCs have been proposed to be responsible for afterdepolarizations after action potentials and for regulating the excitability of the neurons. It may also contribute 
to nerve regeneration after axotomy, because regulated $\mathrm{CaCC}$ expression was strongly correlated with injuryinduced regenerative growth of sensory neurons in vitro and in vivo (André et al., 2003). Best1 has been shown to be up-regulated by nerve injury and required for $\mathrm{CaCC}$ expression in axotomized sensory neurons. However, there is no significant difference in $\mathrm{CaCC}$ in sensory neurons from Best1 knockout mice compared with wildtype mice, prompting the suggestion that Best3 may have a compensatory effect (Boudes et al., 2009). In the same study, no change of mRNAs for TMEM16A and TMEM16B was found in the DRGs after axotomy.

Liu et al. (2010) showed that the potent allogenic substance bradykinin (BK) simultaneously inhibits Mtype $\mathrm{K}^{+}$channels and activates TMEM16A in nociceptors, and both these effects contribute to membrane depolarization in primary sensory afferents, resulting in the generation of ascending nociceptive signals. This is the first study to demonstrate the functional significance of TMEM16A-mediated CaCCs in sensory neurons. Sensory neurons of the DRG are mixed populations of neurons that mediate information concerning the sensations of touch, temperature, muscle contraction, limb position, and painful stimuli to the spinal cord. Characterization of the expression of TMEM16A in subtypes of DRG neurons will shed light on the function of the channel in sensory information transduction.

CaCCs were also recorded in single cilia of olfactory receptor neurons (Kleene and Gesteland, 1991), photoreceptors in retina (Maricq and Korenbrot, 1988; Lalonde et al., 2008), and sensory neurons in mouse vomeronasal organ (Yang and Delay, 2010). Recent studies indicated that TMEM16B seems to be the CaCC expressed in the cilia olfactory sensory neurons and presynaptic terminals of retinal photoreceptors (Stephan et al., 2009; Hengl et al., 2010; Rasche et al., 2010). It noteworthy that a patient with von Willebrand's disease type 3 as a result of deletion of chromosome 22, including part of the TMEM16B gene, seems to lack a sense of smell (Stephan et al., 2009). Indeed, disruption of TMEM16B in mice virtually abolished CaCC currents in the olfactory epithelium and in the vomeronasal organ (Fig. 2D). However, TMEM16B knockout mice showed little defect in olfactory behavioral tasks, leading to the conclusion that, in contrast with the current view, cyclic nucleotide-gated cation channels do not need a boost by $\mathrm{Cl}^{-}$channels to achieve near-physiological levels of olfaction (Billig et al., 2011).

\section{E. Interstitial Cells of Cajal}

High expression of TMEM16A has been found in GISTs, which are some of the most common mesenchymal tumors of the GI tract (Hwang et al., 2011). GISTs are generally thought to arise from interstitial cells of Cajal (ICCs), which are known to be the pacemaker cells and control the contraction of smooth muscle cells of the GI tract (Barajas-López et al., 1989; Rumessen and
Thuneberg, 1996). The pacemaker activity generated by the ICCs induces rhythmic slow waves in the electrically coupled smooth-muscle cells, thereby controlling the phasic contractions of GI muscles to mediate gastric peristalsis and intestinal segmentation (Sanders et al., 2006). CaCCs have been implicated in generating the pacemaker potentials in the ICCs (Parsons and Sanders, 2008). Indeed, TMEM16A protein is expressed abundantly and specifically in ICCs, but not in the smooth muscle cells of the mouse, nonhuman primate, and human GI tracts. The slow wave fails to develop, and proper smooth muscle contractions in the stomach are perturbed in the TMEM16A knockout mice (GomezPinilla et al., 2009; Huang et al., 2009; Hwang et al., 2009) (Fig. 2C). A more recent study showed that expression of alternative splice variants of TMEM16A in ICCs is altered in human diabetic gastroparesis, and the novel variant without exons 1 and 2 and part of exon 3 produces smaller $\mathrm{Ca}^{2+}$-activated $\mathrm{Cl}^{-}$currents that exhibit slower kinetics compared with the full-length TMEM16A in HEK cells. The authors speculate that this may directly contribute to the GI motility disorder in diabetic patients (Mazzone et al., 2011). The critical role of TMEM16A in the pacemaker activity of ICCs and control of smooth muscle phasic contractions in GI tract presents a well illustrated example of the physiological significance of this channel.

\section{Transmembrane Protein 16A Structure and Function}

Before the discovery of TMEM16A as a CaCC, the TMEM16 family was assigned to an eukaryotic protein superfamily known as DUF (domain of unknown function) 590, about which little is known. The conserved DUF590 domain corresponds to the series of eight predicted transmembrane domains in TMEM16 proteins and the short putative cytosolic loops between them. Pairwise alignment of various TMEM16 members from yeast to human on the PANDIT database gives an average of $28 \%$ identity in the DUF590 domain [http:// www.ebi.ac.uk/goldman-srv/pandit (Whelan et al., 2003)]. In general, conservation is reduced away from the transmembrane domains. The $\mathrm{N}$ and $\mathrm{C}$ termini, which form the bulk of the cytosolic portion of the channel, are highly divergent across species and within members of the mammalian TMEM16 family.

DUF590 will most likely prove to be structurally novel. It remains to be determined whether calcium and voltage-sensing determinants are conserved in the DUF590 superfamily, and thus it is still uncertain whether DUF590 family members generally function as calcium-activated chloride channels.

\section{A. The Topology of Transmembrane Protein 16A}

Bioinformatic hydropathy analysis predicts that TMEM16A has eight transmembrane domains with cy- 
tosolic $\mathrm{N}$ and $\mathrm{C}$ termini (see Fig. 3). A hemagglutinin-tag accessibility study of a different TMEM16 family member predicts the same basic topology (Das et al., 2008; Matchkov et al., 2008).

\section{B. Stoichiometry}

TMEM16A interacts with itself and has been observed as a homodimer in chemical cross-linking and native polyacrylamide gel electrophoresis experiments (Fallah et al., 2011; Sheridan et al., 2011). Förster resonance energy transfer experiments also observe that the multimerization of the protein occurs intracellularly before the channel is trafficked to the plasma membrane (Sheridan et al., 2011). The domains involved in multimerization are unknown, and it remains to be determined whether the proposed dimer has two pores, like the CLC family of voltage gated chloride channels. Hetero-oligomerization with other family members or as-yet-unidentified auxiliary subunits remains a possibility that might give rise to heterogeneity of the properties and functions of TMEM16A.

\section{Biophysical Properties of Transmembrane Protein 16A}

Electrophysiological data accumulated over the years has built up a thorough biophysical description of the endogenous $\mathrm{CaCC}$ from various tissues: currents arise from small conductance channels activated by low to submicromolar concentrations of cytosolic calcium in a voltage- and time-dependent manner, and this voltage and time dependence is reduced at higher concentrations of calcium. The "classic" $\mathrm{CaCC}$ was also observed to have modest ionic selectivity, with $\mathrm{Na}^{+}$only 10 times less permeable than $\mathrm{Cl}^{-}$. Bulkier anions such as $\mathrm{SCN}^{-}$,
$\mathrm{I}^{-}$, and $\mathrm{Br}^{-}$have greater permeability than $\mathrm{Cl}^{-}$(Evans and Marty, 1986; Kuruma and Hartzell, 2000).

TMEM16A recapitulates all of these properties. Yang et al. (2008) report the $\mathrm{EC}_{50}$ of calcium-dependent activation for TMEM16A to be $2.6 \mu \mathrm{M}$ at $-60 \mathrm{mV}$ and 0.3 $\mu \mathrm{M}$ at $+60 \mathrm{mV}$. TMEM16A single-channel conductance was determined to be $8.6 \mathrm{pS}$ in HEK293 cells, similar to that reported for endogenous CaCCs. Various aspects of permeation were also determined to be similar between the classic CaCC and TMEM16A expressed in HEK293 cells (Yang et al., 2008) and Axolotl oocytes (Schroeder et al., 2008).

TMEM16A and -B are channels that are activated by cytosolic calcium and modulated by voltage at low calcium concentrations. How or whether these characteristics can be attributed to specific modules on the protein remains unknown. TMEM16A, TMEM16B, and the rest of the family do not share significant homology to any other known family of ion channels, confounding attempts to draw comparisons with established calcium and voltage sensing mechanisms.

\section{Calcium Sensing}

TMEM16A displays a rather high sensitivity to calcium, activating at submicromolar concentrations. The Hill coefficient of calcium binding is more than one, suggesting that multiple calcium ions are required to activate the channel (Kuruma and Hartzell, 2000; Yang et al., 2008). However, typical high-affinity calcium binding sites such as EF hands and C2 domains cannot be identified from the primary protein sequence of TMEM16A or -B. Another well characterized high-affinity calcium binding motif can be found in large-conductance potassium (BK) channels, in which an unusually
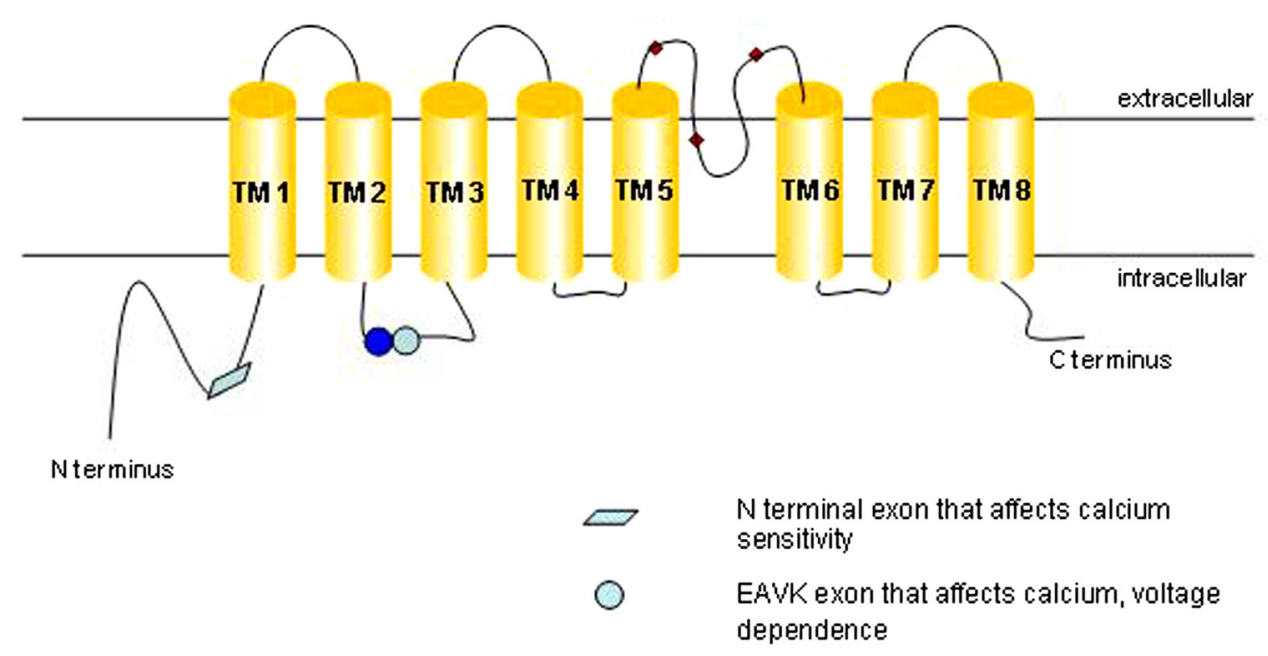

Proposed "calcium bow"

- Basic residues that confer anionic selectivity 
high density of negative charges in a cytosolic domain was found to be critical to micromolar-range calcium sensing in the channel. Strikingly, this "calcium bowl" motif was found to be the longest completely conserved domain in the channel, more highly conserved across species than the signature sequence of the potassium channel selectivity filter (Schreiber and Salkoff, 1997).

In the TMEM16 family, there are no clusters of acidic residues with comparable conservation and significance. The first cytosolic loop [between the second transmembrane segment (TM2) and TM3] has a short string of glutamate residues that has been speculated to contain a $\mathrm{Ca}^{2+}$ binding site akin to the BK channel calcium bowl (Schreiber and Salkoff, 1997; Ferrera et al., 2010). A mutant form of TMEM16A with four consecutive glutamate-to-alanine mutations in the proposed calcium bowl modestly lowered the apparent calcium sensitivity of the channel (Xiao et al., 2011). The same study reports that the removal of a short four-amino acid exon (EAVK) adjacent to the glutamate string reduces apparent calcium sensitivity of TMEM16A to a greater extent. Another naturally occurring splice variant of TMEM16A lacking a 26-amino acid exon in the $\mathrm{N}$ terminus has been reported to be more calcium-sensitive (Ferrera et al., 2009; Xiao et al., 2011). A minimal isoform of TMEM16A lacking all four alternatively spliced exons gives rise to robust $\mathrm{CaCC}$, showing that calcium-sensing elements are still present in this truncated form of the protein (Ferrera et al., 2011). A bona fide calcium binding site remains to be conclusively identified and might be formed from disparate regions on the channel.

It has also been observed that the classic CaCC (Evans and Marty, 1986; Qu and Hartzell, 2000) and heterologously expressed TMEM16A (Xiao et al., 2011) seem to have decreased calcium dependence upon exposure to different permeant anions, raising the possibility that anion-channel interactions couple to calcium and voltage sensing and the gating process.

It is also possible that an auxiliary protein binds to and mediates TMEM16A activation upon an increase in intracellular calcium levels. Calmodulin has been postulated to carry out such a function. This small protein binds calcium with submicromolar affinity and undergoes dramatic conformational change upon binding calcium. Given calmodulin's well known role as the calcium sensor for the small-conductance calcium-activated potassium channels (Xia et al., 1998), it is tempting to envision a similar scenario for the calcium-activated chloride channel. Indeed, dominant-negative mutants of calmodulin were shown to reduce the calcium sensitivity of CaCCs in olfactory sensory neurons (Kaneko et al., 2006), which some reports suggest is probably mediated by TMEM16B (Stephan et al., 2009; Hengl et al., 2010; Rasche et al., 2010). However, perfusing calmodulin over giant excised inside-out patches of heterologously expressed TMEM16B failed to rescue the loss of channel activity that occurs over time in these experiments (Pifferi et al., 2009a).

Tian et al. (2011) reported that calmodulin can be coimmunoprecipitated with TMEM16A and that calmodulin inhibitors decreased whole-cell currents of TMEM16A. Given the ubiquity of calmodulin in numerous cell processes and its role in calcium-activated calcium release (Patel et al., 1999), it remains to be proven that calmodulin directly gated the channel.

\section{E. Voltage Sensing}

At low calcium concentrations, TMEM16A and -B are preferentially activated at positive membrane potentials. Conversely, positive membrane potentials confer upon the channels higher calcium sensitivity. One plausible explanation is that the calcium-binding sites lie within the electric field of the membrane and have increased cytosolic exposure upon membrane depolarization as a result of conformational changes in the protein.

Clues to identifying the voltage-sensing module in TMEM16A come from the study of its splice variants. The minimal TMEM16A isoform that has shorter intracellular domains gives rise to a channel that is time- and voltage-independent (Caputo et al., 2008; Ferrera et al., 2009; Ferrera et al., 2011). In particular, the first cytosolic loop has been implicated in voltage-dependent modulation of the channel. TMEM16A lacking the EAVK exon was reported to have significantly reduced voltage dependence (Ferrera et al., 2009). Another study reported that TMEM16A could be activated purely by voltage and that under calcium-free conditions, removal of the same EAVK exon did not give rise to voltage-independent currents but rather increased $\mathrm{Ca}^{2+}$-independent currents at highly depolarized potentials, suggesting stabilization of a voltage-gated open state (Xiao et al., 2011).

In traditional voltage-gated ion channels, the $\mathrm{S} 4$ domain is believed to be the primary voltage sensing module. This transmembrane domain has a series of charged residues spaced evenly between hydrophobic residues, poised to sense voltage changes across the membrane. Although charged residues are present in the predicted transmembrane regions of TMEM16A and -B, they are sporadic and appear without the regularity that is apparent in the S4 domain. Thus, it is unclear that the voltage sensor model, characteristic of voltage-gated potassium, sodium, and calcium channels, applies to TMEM16A and its family members.

In conclusion, it remains to be determined how voltage modulates TMEM16A channel function and how calcium and voltage couple to modulate channel gating.

\section{F. Molecular Determinants of Ion Permeation/Permeability}

A re-entrant loop between TM5 and TM6 has been proposed to form the pore of the channel. Mutating conserved basic residues to acidic residues in this region 
was reported to increase the relative permeability of $\mathrm{Na}^{+}$over $\mathrm{Cl}^{-}$. This was confirmed by the observation that mutagenesis of cysteines to alanines in the putative pore region abolished [2-(trimethylammonium)ethyl] methanethiosulfonate bromide-induced block seen in wild-type channels (Yang et al., 2008). It is interesting to note that ion permeation pathways of anion-selective channels are often observed to lie within electropositive environments that are the result of helix-dipole interactions, as well as main- and side-chain amide and hydroxyl groups bearing partial, not full, positive charges (Dutzler et al., 2002; Hibbs and Gouaux, 2011). It is thus conceivable that similar principles contribute to anion coordination and permeation in TMEM16A.

As was observed with classic endogenous CaCCs, TMEM16A favors the passage of bulkier anions, with $\mathrm{NO}_{3}^{-}, \mathrm{I}^{-}$, and $\mathrm{Br}^{-}$more permeable than $\mathrm{Cl}^{-}$(Schroeder et al., 2008; Yang et al., 2008). There have also been reports that the ionic selectivity of TMEM16A and -B shifts over the course of channel activation (Schroeder et al., 2008; Sagheddu et al., 2010). This could be due to a flexible pore that allows multiple open states of the channel to be sampled as changes in local calcium concentration occur, with more selective open states occurring at higher calcium concentrations (Sagheddu et al., 2010). The existence of multiple open states was reported in rabbit pulmonary artery smooth muscle CaCC (Piper and Large, 2003), and a similar phenomenon has been observed (Boton et al., 1989) and computationally predicted in $X$. laevis CaCC (Kuruma and Hartzell, 2000). Techniques with higher molecular resolution will be required to reveal the exact determinants of anionic selectivity and permeation.

\section{G. Pharmacology}

It has been speculated that the modulation of TMEM16A activity in various epithelial tissues presents an opportunity for therapeutic intervention in pathological conditions such as cystic fibrosis, hypertension, asthma, and diarrhea. However, it remains an ongoing challenge to develop compounds that potently and specifically modulate CaCCs.

Traditionally, endogenous CaCCs have been inhibited through the use of compounds such as NFA, 4,4'-diisothiocyanatostilbene-2,2'-disulfonic acid, and 5-nitro-2(3-phenylpropylamino)benzoic acid. These compounds have been shown to inhibit TMEM16A current with mid-micromolar potency, and are nonspecific compounds that target chloride channels in general, including the CFTR channel and the voltage-gated chloride channel (ClC) family.

There have been reports of TMEM16A-specific inhibitors. Namkung et al. (2011) found that siRNA of TMEM16A effectively reduces only an early transient current that arises from UTP stimulation of human bronchial epithelial cells taken from patients with cystic fibrosis. The authors went on to identify a compound that also specifically inhibits this early transient current; thus, they conclude this compound to be a TMEM16A-specific inhibitor. The prolonged $\mathrm{CaCC}$ after this initial transient was only inhibited by compounds described previously as broad-spectrum CaCC inhibitors (Namkung et al., 2010; Namkung et al., 2011). These results cast doubts on the contribution of TMEM16A to agonist-stimulated airway epithelial CaCCs. A thorough understanding of the contribution of TMEM16A activity to the normal and disease states of various epithelia needs to be developed for TMEM16A-based therapeutics to become a reality.

There have also been discrepancies in the literature over the efficacy of certain drugs as TMEM16A inhibitors. Tamoxifen has been reported to inhibit the endogenous $\mathrm{CaCC}$ in bovine pulmonary artery endothelial cells (Nilius et al., 1997) but not other types of tissue (Winpenny et al., 1998; Qu et al., 2003), apparently as a result of clustering of $\mathrm{CaCC}$ s with BK channels (Davis et al., 2010). The same compound inhibited TMEM16A current in HEK 293 cells (Yang et al., 2008) but not in Axolotl oocytes (Schroeder et al., 2008).

In murine portal vein myocytes in which TMEM16A immunoreactivity was detected, CaCCs were shown to be sensitive to tamoxifen and paxillin, blockers of the $\mathrm{BK}_{\mathrm{Ca}}$ (large-conductance calcium-activated potassium) channel. Pretreating the cells with methyl- $\beta$-cyclodextrin relieves this sensitivity, suggesting that $\mathrm{BK} / \mathrm{CaCC}$ protein interactions within lipid microdomains affect the pharmacological profile of CaCC (Sones et al., 2010). In conclusion, tissue-specific factors might contribute to the observed disparities in the pharmacology of this channel.

\section{H. Phosphorylation}

Endogenous CaCCs are probably regulated by kinase activity. In rabbit arterial and portal vein smooth muscle cells, dialyzing adenylyl imidodiphosphate, a nonhydrolyzable ATP analog, into cells reduces the loss of channel activity over time (Angermann et al., 2006). Phosphatase inhibitors also antagonize the recovery of CaCC after initial run-down (Ayon et al., 2009). CaMKII in particular has been associated with inhibition of CaCCs in pulmonary artery smooth muscle (Greenwood et al., 2001). The authors report that the commonly used CaMKII inhibitors 2-( $N$-[2-hydroxyethyl])- $N$-(4-methoxybenzenesulfonyl)amino- $N$-(4-chlorocinnamyl)- $N$-methylamine (KN-93) and autocamtide-2-related CaMKII inhibitory peptide enhance the amplitude and apparent open probability of $\mathrm{CaCCs}$ in this tissue. In addition, dialyzing constitutively active CaMKII into pulmonary artery smooth muscle cells reduced $\mathrm{CaCC}$ amplitude. These observations are of particular interest because of reports suggesting that TMEM16A mediates the rat pulmonary arterial smooth muscle CaCC (Manoury et al., 2010).

Primary sequence analysis of mammalian TMEM16A shows putative phosphorylation sites for protein kinases 
A, C, and G, as well as CaMKII and casein kinase. However, TMEM16A activity in HEK 293 cells is not significantly affected by either staurosporine, a nonspecific kinase inhibitor, or the CaMKII inhibitor KN93 (Tian et al., 2011) . This raises the possibility that in native tissue, tissue-specific factors mediate TMEM16A kinase sensitivity.

\section{Glycosylation}

Upon treatment with $N$-glycosidase F, the observed molecular weight of TMEM16A on an SDS-polyacrylamide gel decreases (Yang et al., 2008; Fallah et al., 2011), indicating that the channel is glycosylated. Plasma membrane-bound TMEM16A is Endo H-insensitive, in that protein mobility on SDS-polyacrylamide gel electrophoresis is unchanged after treatment with the enzyme, indicating a mature complex-glycosylated ion channel (Fallah et al., 2011). Some glycosylation sites are conserved in the TMEM16 family (Das et al., 2008), but the significance of glycosylation on TMEM16A function remains unknown.

\section{Transmembrane Protein 16A Family Members and Disease Correlations}

As discussed above, TMEM16A is up-regulated in some tumors, and mice lacking TMEM16A do not thrive and have abnormalities in tracheal development and gut contraction. CaCCs have been identified as a therapeutic target in cystic fibrosis and asthma (Duran et al., 2010), and the discovery of TMEM16A as a bona fide $\mathrm{CaCC}$ enables further studies on its potential role in those diseases.

There are a total of 10 members in the vertebrate TMEM16 family (see the phylogenetic analysis in Fig. 4). Sequence similarity and phylogenetic analysis shows that TMEM16B shares the highest sequence homology with TMEM16A, with $56.5 \%$ sequence identity and $71.4 \%$ sim- ilarity. TMEM16C and TMEM16D share 58.9\% sequence identity and $72.2 \%$ similarity. TMEM16E and TMEM16F are $46.8 \%$ identical and $64.6 \%$ similar. TMEM16H and TMEM16K might constitute a subfamily of TMEM16 proteins, because they are genetically distant from the other eight members of the family in the phylogenetic tree.

Besides TMEM16A, TMEM16B is the only member so far that has been shown to function as a $\mathrm{CaCC}$ in heterologous expression systems, and it may account for the endogenous $\mathrm{CaCC}$ in olfactory cilia and retinal synapses (Schroeder et al., 2008; Pifferi et al., 2009a; Stöhr et al., 2009; Rasche et al., 2010; Sagheddu et al., 2010). Disruption of TMEM16B in mice virtually abolished $\mathrm{Ca}^{2+}$. activated $\mathrm{Cl}^{-}$currents in the main olfactory epithelium (MOE) and in the vomeronasal organ. TMEM16B disruption reduced fluid-phase electro-olfactogram responses by only $\sim 40 \%$, did not change air-phase electroolfactograms, and did not reduce performance in olfactory behavioral tasks, so the authors conclude that CaCCs are dispensable for near-normal olfaction (Billig et al., 2011). A homozygous deletion of part of the TMEM16B gene has been found in severe von Willebrand disease (VWD) type 3 , a hereditary coagulation abnormality in humans caused by defects of the von Willebrand factor III; interestingly, Stephan et al. (2009) cited personal communication with Roswitha Eisert and Reinhard Schneppenheim about the apparent inability to detect smell in a patient homozygous for the 253-kilobase deletion of chromosome 22, including TMEM16B. It would be interesting to determine whether similar observations apply to other patients. It will also be worthwhile to check blood coagulation in the TMEM16B knockout mice (Schneppenheim et al., 2007; Billig et al., 2011). TMEM16B is also expressed in retinal synapses and brain (Stöhr et al., 2009), but the physiological significance of TMEM16B in these organs awaits further elucidation. TMEM16B has been found in

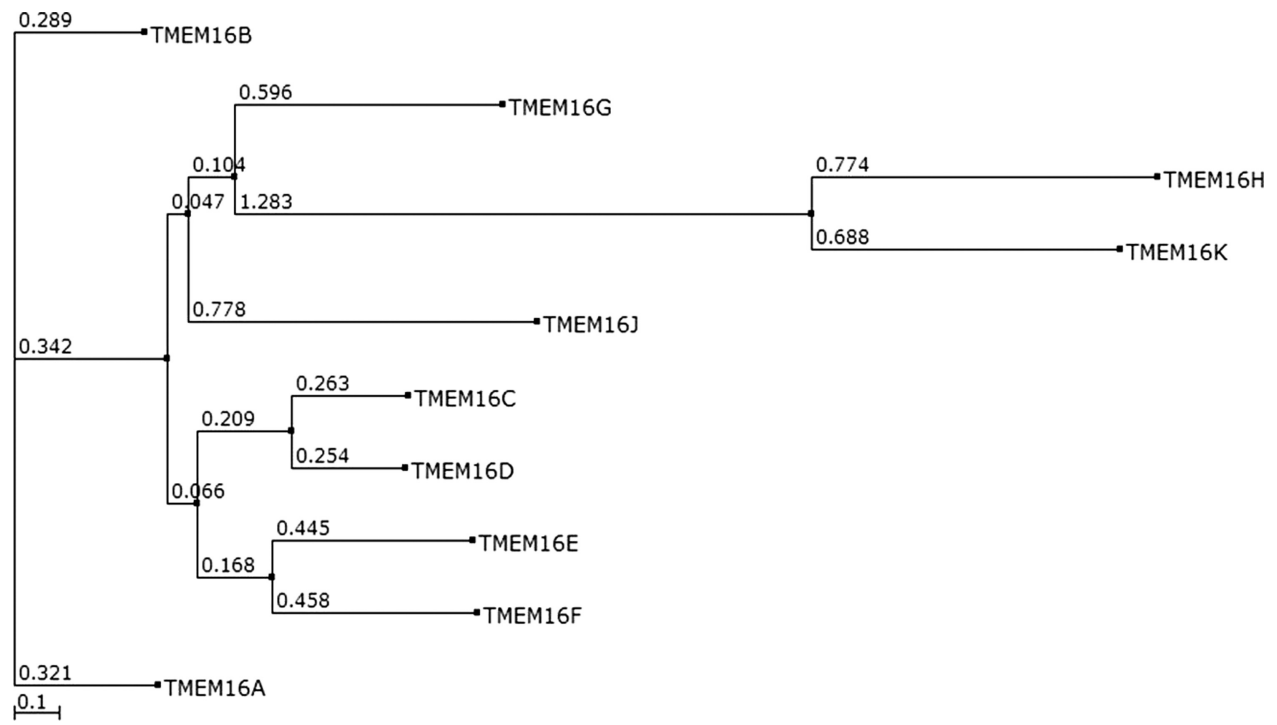

FIG. 4. Phylogenetic analysis of 10 members of mouse TMEM16 proteins. 
association with panic disorder in a genome-wide association study in the Japanese population, but its significance could not be replicated in later studies (Otowa et al., 2009, 2010).

TMEM16E, also known as GDD1, is linked to gnathodiaphyseal dysplasia, a rare skeletal syndrome characterized by bone fragility, sclerosis of tubular bones, and cemento-osseous lesions of the jawbone. Mutation of human TMEM16E has been found in TMEM16E (Tsutsumi et al., 2004, 2005; Mizuta et al., 2007).

Recessive mutations in TMEM16E have been found in a proximal limb-girdle muscular dystrophy (LGMD2L) and in a distal nondysferlin Miyoshi myopathy (MMD3) (Bolduc et al., 2010). Immunohistochemical analysis showed a high level of murine TMEM16E protein expression in cardiac and skeletal muscle tissues and in growth-plate chondrocytes and osteoblasts in bone. When heterologously expressed, TMEM16E resides in intracellular membrane compartments, so it is unknown whrther it serves as a CaCC in the plasma membrane (Mizuta et al., 2007).

Recent studies have found that TMEM16F is an essential component for mediating the $\mathrm{Ca}^{2+}$-dependent exposure of phosphatidylserine (PtdSer) on the cell surface. When blood platelets are activated, they expose phosphatidylserine (PtdSer) to trigger the clotting system. The PtdSer exposure is mediated by $\mathrm{Ca}^{2+}$-dependent phospholipid scramblases that transport phospholipids bidirectionally.

A constitutively active mutant of TMEM16F was discovered to be critical for enhancing the spontaneous exposure of PtdSer in a mouse B cell subline. An A-to-G mutation at nucleotide 1226 caused an aspartate residue to be replaced by glycine at codon 409 in TMEM16F, which is then sensitized to expose PtdSer at normal intracellular concentrations of $\mathrm{Ca}^{2+}$. A frame-shift mutation with skipping of exon 13 in TMEM16F was found in a patient with Scott syndrome, a rare congenital bleeding disorder that is due to a defective platelet mechanism required for blood coagulation (Suzuki et al., 2010; Castoldi et al., 2011). The overexpression of TMEM16A in Ba/F3 cells had no effect on the ionophorea cysteine residue in a predicted extracellular loop of

induced exposure of PtdSer, suggesting that different members of this family have distinct functions (Suzuki et al., 2010). More recently, two more mutations in TMEM16F were found in another Scott syndrome patient: a transition at the first nucleotide of intron 6 , disrupting the donor splice site consensus sequence of intron 6 , and a single-nucleotide insertion in exon 11 , predicting a frame shift and premature termination of translation at codon 411 (Castoldi et al., 2011). It will be interesting to determine whether TMEM16F functions as a channel at all, and if it does, how it functionally correlates with scramblase activity.

TMEM16G, also known as NGEP, has been found in prostate cancer and normal prostate. RNA analysis revealed two splice variants of TMEM16G mRNA: a short form encoding a soluble protein and a long form encoding a polytopic membrane protein. Overexpression of TMEM16G in the prostate cancer cell line LNCaP promotes formation of large cell aggregates (Bera et al., 2004; Das et al., 2007). However, the exact role of TMEM16G in prostate is unknown. In a recent study with targeted next-generation sequencing technology, a TMEM16K mutation was found in autosomal-recessive cerebellar ataxia (Vermeer et al., 2010).

\section{Conclusion}

TMEM16A, a member of the TMEM16 family, is responsible for the classic $\mathrm{CaCC}$ in multiple cell types. It recapitulates the biophysical properties of endogenous CaCCs, including activation by submicromolar calcium, outward rectification, anion selectivity, and pharmacological inhibition by traditional chloride channel inhibitors. Expression of TMEM16A has been found in a variety of cell types, such as epithelial cells, smooth muscle cells, pace-making cells in GI tracts, and sensory neurons. Its physiological significance is under extensive investigation. Mice lacking TMEM16A do not thrive, and they display abnormalities in tracheal development and gut movement. Conditional knockout mice will be ideal for teasing out the physiological significance of TMEM16A in different cell types, as well as its potential involvement in diseases such as cystic fibrosis, asthma,

TABLE 1

Physiological function and diseases correlation of TMEM16 family members

\begin{tabular}{|c|c|c|}
\hline Family Members & Function and Diseases Correlation & References \\
\hline TMEM16A & $\begin{array}{l}\text { Tracheomalacia; gastrointestinal motility; pain sensation; GIST; } \\
\text { salivary gland secretion; airway epithelial secretion. }\end{array}$ & $\begin{array}{l}\text { Rock et al., 2008, 2009; Huang et al., } \\
\text { 2009; Hwang et al., 2009; Romanenko } \\
\text { et al., 2010; Hwang et al., 2011; } \\
\text { Mazzone et al., } 2011\end{array}$ \\
\hline TMEM16B & $\begin{array}{l}\text { Photoreceptor signal in retina; olfaction signal transduction in } \\
\text { sensory neurons. }\end{array}$ & $\begin{array}{l}\text { Stephan et al., 2009; Stöhr et al., 2009; } \\
\text { Rasche et al., 2010; Billig et al., } 2011\end{array}$ \\
\hline TMEM16E & $\begin{array}{l}\text { Gnathodiaphyseal dysplasia; proximal limb-girdle muscular } \\
\text { dystrophy; distal non-dysferlin Miyoshi myopathy. }\end{array}$ & $\begin{array}{l}\text { Kleene and Gesteland, 1991; Tsutsumi } \\
\text { et al., 2004; Mizuta et al., } 2007\end{array}$ \\
\hline TMEM16F & $\begin{array}{l}\mathrm{Ca}^{2+} \text {-dependent phospholipid scramblases for PtdSer exposure } \\
\text { in platelets; mutations found in Scott syndrome. }\end{array}$ & Suzuki et al., 2010; Castoldi et al., 2011 \\
\hline TMEM16G & Expression in prostate cancer and normal prostate. & Bera et al., 2004; Das et al., 2007 \\
\hline TMEM16K & Mutation found in autosomal-recessive cerebellar ataxia. & Vermeer et al., 2010 \\
\hline
\end{tabular}


and cancer. Much remains to be learned about the structure-function relationships of the channel, including its stoichiometry, calcium- and voltage-sensing modules, and the channel-gating mechanism. Pharmacological tools specific for this channel are not yet available and would greatly facilitate biophysical studies and the development of TMEM16A as a therapeutic target.

Besides TMEM16A, TMEM16B is the only TMEM16 family member that has been shown to be a $\mathrm{CaCC}$ and is expressed in the olfaction epithelium and retinal synapses. It is unknown whether the other eight members are also CaCCs or if they function as channels. Several members of the TMEM16 family have been implicated in human diseases (Table 1 for summary). Their physiological significance warrants future study of the TMEM16 family.

\section{Acknowledgments}

This work was supported by the National Institutes of Health National Institute of Neurological Disorders and Stroke [Grant NS069229] and the Howard Hughes Medical Institute. We thank Jim Berg and Huanghe Yang for discussions and editing of the manuscript.

\section{Authorship Contributions}

Wrote or contributed to the writing of the manuscript: Huang, Wong, and Jan.

\section{References}

Agnel M, Vermat T, and Culouscou JM (1999) Identification of three novel members of the calcium-dependent chloride channel $(\mathrm{CaCC})$ family predominantly expressed in the digestive tract and trachea. FEBS Lett 455:295-301.

Al-Jumaily M, Kozlenkov A, Mechaly I, Fichard A, Matha V, Scamps F, Valmier J, and Carroll P (2007) Expression of three distinct families of calcium-activated chloride channel genes in the mouse dorsal root ganglion. Neurosci Bull 23:293299.

al-Nakkash L and Cotton CU (1997) Bovine pancreatic duct cells express cAMP- and $\mathrm{Ca}^{2+}$-activated apical membrane $\mathrm{Cl}^{-}$conductances. Am J Physiol 273:G204G216.

Anderson MP and Welsh MJ (1991) Calcium and cAMP activate different chloride channels in the apical membrane of normal and cystic fibrosis epithelia. Proc Natl Acad Sci USA 88:6003-6007.

André S, Boukhaddaoui H, Campo B, Al-Jumaily M, Mayeux V, Greuet D, Valmier J, and Scamps F (2003) Axotomy-induced expression of calcium-activated chloride current in subpopulations of mouse dorsal root ganglion neurons. $J$ Neurophysiol 90:3764-3773.

Angermann JE, Sanguinetti AR, Kenyon JL, Leblanc N, and Greenwood IA (2006) Mechanism of the inhibition of $\mathrm{Ca}^{2+}$-activated $\mathrm{Cl}^{-}$currents by phosphorylation in pulmonary arterial smooth muscle cells. J Gen Physiol 128:73-87.

Ayon R, Sones W, Forrest AS, Wiwchar M, Valencik ML, Sanguinetti AR, Perrino BA, Greenwood IA, and Leblanc N (2009) Complex phosphatase regulation of $\mathrm{Ca}^{2+}$-activated $\mathrm{Cl}^{-}$currents in pulmonary arterial smooth muscle cells. J Biol Chem 284:32507-32521.

Bader CR, Bertrand D, and Schwartz EA (1982) Voltage-activated and calciumactivated currents studied in solitary rod inner segments from the salamander retina. J Physiol 331:253-284.

Bao R, Lifshitz LM, Tuft RA, Bellvé K, Fogarty KE, and ZhuGe R (2008) A close association of RyRs with highly dense clusters of $\mathrm{Ca}^{2+}$-activated $\mathrm{Cl}^{-}$channels underlies the activation of STICs by $\mathrm{Ca}^{2+}$ sparks in mouse airway smooth muscle. $J$ Gen Physiol 132:145-160.

Barajas-López C, Berezin I, Daniel EE, and Huizinga JD (1989) Pacemaker activity recorded in interstitial cells of Cajal of the gastrointestinal tract. Am J Physiol 257:C830-C835.

Barish ME (1983) A transient calcium-dependent chloride current in the immature Xenopus oocyte. J Physiol 342:309-325.

Barrett KE and Keely SJ (2000) Chloride secretion by the intestinal epithelium molecular basis and regulatory aspects. Annu Rev Physiol 62:535-572.

Bera TK, Das S, Maeda H, Beers R, Wolfgang CD, Kumar V, Hahn Y, Lee B, and Pastan I (2004) NGEP, a gene encoding a membrane protein detected only in prostate cancer and normal prostate. Proc Natl Acad Sci USA 101:3059-3064.

Berecki G, Varga Z, Van Iren F, and Van Duijn B (1999) Anion channels in chara corallina tonoplast membrane: calcium dependence and rectification. $J \mathrm{Membr}$ Biol 172:159-168.

Bernheim L, Bader CR, Bertrand D, and Schlichter R (1989) Transient expression of a $\mathrm{Ca}^{2+}$-activated $\mathrm{Cl}^{-}$current during development of quail sensory neurons. Dev Biol 136:129-139.
Billig GM, Pál B, Fidzinski P, and Jentsch TJ (2011) $\mathrm{Ca}^{2+}$-activated $\mathrm{Cl}^{-}$currents are dispensable for olfaction. Nat Neurosci 14:763-769

Bolduc V, Marlow G, Boycott KM, Saleki K, Inoue H, Kroon J, Itakura M, Robitaille Y, Parent L, Baas F, et al. (2010) Recessive mutations in the putative calciumactivated chloride channel Anoctamin 5 cause proximal LGMD2L and distal MMD3 muscular dystrophies. Am J Hum Genet 86:213-221.

Boton R, Dascal N, Gillo B, and Lass Y (1989) Two calcium-activated chloride conductances in Xenopus laevis oocytes permeabilized with the ionophore A23187. $J$ Physiol 408:511-534.

Boudes M, Sar C, Menigoz A, Hilaire C, Péquignot MO, Kozlenkov A, Marmorstein A, Carroll P, Valmier J, and Scamps F (2009) Best1 is a gene regulated by nerve injury and required for $\mathrm{Ca}^{2+}$-activated $\mathrm{Cl}^{-}$current expression in axotomized sensory neurons. J Neurosci 29:10063-10071.

Caputo A, Caci E, Ferrera L, Pedemonte N, Barsanti C, Sondo E, Pfeffer U, Ravazzolo R, Zegarra-Moran O, and Galietta LJ (2008) TMEM16A, a membrane protein associated with calcium-dependent chloride channel activity. Science 322:590594

Castoldi E, Collins PW, Williamson PL, and Bevers EM (2011) Compound heterozygosity for 2 novel TMEM16F mutations in a patient with Scott syndrome. Blood 117:4399-4400.

Cross NL (1981) Initiation of the activation potential by an increase in intracellular calcium in eggs of the frog, Rana pipiens. Dev Biol 85:380-384.

Cross NL and Elinson RP (1980) A fast block to polyspermy in frogs mediated by changes in the membrane potential. Dev Biol 75:187-198.

Cunningham SA, Awayda MS, Bubien JK, Ismailov II, Arrate MP, Berdiev BK, Benos DJ, and Fuller CM (1995) Cloning of an epithelial chloride channel from bovine trachea. J Biol Chem 270:31016-31026.

Cuthbert AW (2011) New horizons in the treatment of cystic fibrosis. Br J Pharmacol 163:173-183

Das S, Hahn Y, Nagata S, Willingham MC, Bera TK, Lee B, and Pastan I (2007) NGEP, a prostate-specific plasma membrane protein that promotes the association of LNCaP cells. Cancer Res 67:1594-1601.

Das S, Hahn Y, Walker DA, Nagata S, Willingham MC, Peehl DM, Bera TK, Lee B, and Pastan I (2008) Topology of NGEP, a prostate-specific cell:cell junction protein widely expressed in many cancers of different grade level. Cancer Res 68:63066312 .

Davis AJ, Forrest AS, Jepps TA, Valencik ML, Wiwchar M, Singer CA, Sones WR Greenwood IA, and Leblanc N (2010) Expression profile and protein translation of TMEM16A in murine smooth muscle. Am J Physiol Cell Physiol 299:C948-C959.

De Castro F, Geijo-Barrientos E, and Gallego R (1997) Calcium-activated chloride current in normal mouse sympathetic ganglion cells. J Physiol 498:397-408.

Duran C, Thompson CH, Xiao Q, and Hartzell HC (2010) Chloride channels: often enigmatic, rarely predictable. Annu Rev Physiol 72:95-121.

Dutzler R, Campbell EB, Cadene M, Chait BT, and MacKinnon R (2002) X-ray structure of a $\mathrm{ClC}$ chloride channel at $3.0 \mathrm{~A}$ reveals the molecular basis of anion selectivity. Nature 415:287-294.

Eggermont J (2004) Calcium-activated chloride channels: (un)known, (un)loved? Proc Am Thorac Soc 1:22-27.

Erle DJ and Zhen G (2006) The asthma channel? Stay tuned... Am J Respir Crit Care Med 173:1181-1182.

Espinosa I, Lee CH, Kim MK, Rouse BT, Subramanian S, Montgomery K, Varma S, Corless CL, Heinrich MC, Smith KS, et al. (2008) A novel monoclonal antibody against DOG1 is a sensitive and specific marker for gastrointestinal stromal tumors. Am J Surg Pathol 32:210-218.

Evans MG and Marty A (1986) Calcium-dependent chloride currents in isolated cells from rat lacrimal glands. $J$ Physiol 378:437-460.

Fallah G, Romer T, Detro-Dassen S, Braam U, Markwardt F, and Schmalzing G (2011) TMEM16A(a)/anoctamin-1 shares a homodimeric architecture with CLC chloride channels. Mol Cell Proteomics 10:M110.004697.

Ferrera L, Caputo A, and Galietta LJ (2010) TMEM16A protein: a new identity for $\mathrm{Ca}^{2+}$-dependent $\mathrm{Cl}^{-}$channels. Physiology (Bethesda) 25:357-363.

Ferrera L, Caputo A, Ubby I, Bussani E, Zegarra-Moran O, Ravazzolo R, Pagani F, and Galietta LJ (2009) Regulation of TMEM16A chloride channel properties by alternative splicing. J Biol Chem 284:33360-33368.

Ferrera L, Scudieri P, Sondo E, Caputo A, Caci E, Zegarra-Moran O, Ravazzolo R and Galietta LJ (2011) A minimal isoform of the TMEM16A protein associated with chloride channel activity. Biochim Biophys Acta 1808:2214-2223.

Flores CA, Cid LP, Sepúlveda FV, and Niemeyer MI (2009) TMEM16 proteins: the long awaited calcium-activated chloride channels? Braz J Med Biol Res 42:9931001

Fromm J and Lautner S (2007) Electrical signals and their physiological significance in plants. Plant Cell Environ 30:249-257.

Galietta LJ (2009) The TMEM16 protein family: a new class of chloride channels? Biophys J 97:3047-3053.

Gibson A, Lewis AP, Affleck K, Aitken AJ, Meldrum E, and Thompson N (2005) hCLCA1 and mCLCA3 are secreted non-integral membrane proteins and therefore are not ion channels. J Biol Chem 280:27205-27212.

Gomez-Pinilla PJ, Gibbons SJ, Bardsley MR, Lorincz A, Pozo MJ, Pasricha PJ, Van de Rijn M, West RB, Sarr MG, Kendrick ML, et al. (2009) Ano1 is a selective marker of interstitial cells of Cajal in the human and mouse gastrointestinal tract. Am J Physiol Gastrointest Liver Physiol 296:G1370-G1381.

Greenwood IA, Ledoux J, and Leblanc N (2001) Differential regulation of $\mathrm{Ca}^{2+}$ activated $\mathrm{Cl}(-)$ currents in rabbit arterial and portal vein smooth muscle cells by $\mathrm{Ca}^{2+}$-calmodulin-dependent kinase. $J$ Physiol 534:395-408.

Gritli-Linde A, Vaziri Sani F, Rock JR, Hallberg K, Iribarne D, Harfe BD, and Linde A (2009) Expression patterns of the Tmem16 gene family during cephalic development in the mouse. Gene Expr Patterns 9:178-191.

Hartzell C, Putzier I, and Arreola J (2005) Calcium-activated chloride channels. Annu Rev Physiol 67:719-758.

Hartzell HC, Qu Z, Yu K, Xiao Q, and Chien LT (2008) Molecular physiology of 
bestrophins: multifunctional membrane proteins linked to best disease and other retinopathies. Physiol Rev 88:639-672.

Hengl T, Kaneko H, Dauner K, Vocke K, Frings S, and Möhrlen F (2010) Molecular components of signal amplification in olfactory sensory cilia. Proc Natl Acad Sci USA 107:6052-6057.

Hibbs RE and Gouaux E (2011) Principles of activation and permeation in an anion-selective Cys-loop receptor. Nature 474:54-60.

Hogg RC, Wang Q, and Large WA (1993) Time course of spontaneous calciumactivated chloride currents in smooth muscle cells from the rabbit portal vein. J Physiol 464:15-31.

Huang F, Rock JR, Harfe BD, Cheng T, Huang X, Jan YN, and Jan LY (2009) Studies on expression and function of the TMEM16A calcium-activated chloride channel. Proc Natl Acad Sci USA 106:21413-21418.

Huang X, Godfrey TE, Gooding WE, McCarty KS Jr, and Gollin SM (2006) Comprehensive genome and transcriptome analysis of the 11q13 amplicon in human oral cancer and synteny to the 7F5 amplicon in murine oral carcinoma. Genes Chromosomes Cancer 45:1058-1069.

Hwang DG, Qian X, and Hornick JL (2011) DOG1 antibody is a highly sensitive and specific marker for gastrointestinal stromal tumors in cytology cell blocks. Am J Clin Pathol 135:448-453.

Hwang SJ, Blair PJ, Britton FC, O’Driscoll KE, Hennig G, Bayguinov YR, Rock JR, Harfe BD, Sanders KM, and Ward SM (2009) Expression of anoctamin 1/TMEM16A by interstitial cells of Cajal is fundamental for slow wave activity in gastrointestinal muscles. J Physiol 587:4887-4904.

Ishikawa T and Cook DI (1993) $\mathrm{A} \mathrm{Ca}^{2+}$-activated $\mathrm{Cl}^{-}$current in sheep parotid secretory cells. J Membr Biol 135:261-271.

Janssen LJ and Sims SM (1992) Acetylcholine activates non-selective cation and chloride conductances in canine and guinea-pig tracheal myocytes. J Physiol 453:197-218

Jentsch TJ, Stein V, Weinreich F, and Zdebik AA (2002) Molecular structure and physiological function of chloride channels. Physiol Rev 82:503-568.

Kaneko H, Möhrlen F, and Frings S (2006) Calmodulin contributes to gating control in olfactory calcium-activated chloride channels. J Gen Physiol 127:737-748.

Kashyap MK, Marimuthu A, Kishore CJ, Peri S, Keerthikumar S, Prasad TS, Mahmood R, Rao S, Ranganathan P, Sanjeeviah RC, et al. (2009) Genomewide mRNA profiling of esophageal squamous cell carcinoma for identification of cancer biomarkers. Cancer Biol Ther 8:36-46.

Kleene SJ and Gesteland RC (1991) Calcium-activated chloride conductance in frog olfactory cilia. J Neurosci 11:3624-3629.

Komiya T, Tanigawa Y, and Hirohashi S (1999) Cloning and identification of the gene gob-5, which is expressed in intestinal goblet cells in mice. Biochem Biophys Res Commun 255:347-351.

Korn SJ and Weight FF (1987) Patch-clamp study of the calcium-dependent chloride current in AtT-20 pituitary cells. J Neurophysiol 58:1431-1451.

Koumi S, Sato R, and Aramaki T (1994) Characterization of the calcium-activated chloride channel in isolated guinea-pig hepatocytes. J Gen Physiol 104:357-373.

Kuruma A and Hartzell HC (2000) Bimodal control of a $\mathrm{Ca}^{2+}$-activated $\mathrm{Cl}(-)$ channel by different $\mathrm{Ca}^{2+}$ signals. J Gen Physiol 115:59-80.

Lalonde MR, Kelly ME, and Barnes S (2008) Calcium-activated chloride channels in the retina. Channels (Austin) 2:252-260.

Lancaster E, Oh EJ, Gover T, and Weinreich D (2002) Calcium and calciumactivated currents in vagotomized rat primary vagal afferent neurons. J Physiol 540:543-556

Large WA and Wang Q (1996) Characteristics and physiological role of the $\mathrm{Ca}^{2+}$ activated $\mathrm{Cl}^{-}$conductance in smooth muscle. Am J Physiol 271:C435-C454.

Lee RJ and Foskett JK (2010) Mechanisms of $\mathrm{Ca}^{2+}$-stimulated fluid secretion by porcine bronchial submucosal gland serous acinar cells. Am J Physiol Lung Cell Mol Physiol 298:L210-L231.

Liu B, Linley JE, Du X, Zhang X, Ooi L, Zhang H, and Gamper N (2010) The acute nociceptive signals induced by bradykinin in rat sensory neurons are mediated by inhibition of M-type $\mathrm{K}^{+}$channels and activation of $\mathrm{Ca}^{2+}$-activated $\mathrm{Cl}^{-}$channels. $J$ Clin Invest 120:1240-1252.

Loewen ME and Forsyth GW (2005) Structure and function of CLCA proteins. Physiol Rev 85:1061-1092.

Manoury B, Tamuleviciute A, and Tammaro P (2010) TMEM16A/anoctamin 1 protein mediates calcium-activated chloride currents in pulmonary arterial smooth muscle cells. J Physiol 588:2305-2314.

Maricq AV and Korenbrot JI (1988) Calcium and calcium-dependent chloride currents generate action potentials in solitary cone photoreceptors. Neuron 1:503515 .

Matchkov VV, Larsen P, Bouzinova EV, Rojek A, Boedtkjer DM, Golubinskaya V, Pedersen FS, Aalkjaer C, and Nilsson H (2008) Bestrophin-3 (vitelliform macular dystrophy 2-like 3 protein) is essential for the cGMP-dependent calcium-activated chloride conductance in vascular smooth muscle cells. Circ Res 103:864-872.

Mayer ML (1985) A calcium-activated chloride current generates the afterdepolarization of rat sensory neurones in culture. J Physiol 364:217-239.

Mazzone A, Bernard CE, Strege PR, Beyder A, Galietta LJ, Pasricha PJ, Rae JL, Parkman HP, Linden DR, Szurszewski JH, et al. (2011) Altered expression of Ano1 variants in human diabetic gastroparesis. J Biol Chem 286:13393-13403.

Melvin JE, Yule D, Shuttleworth T, and Begenisich T (2005) Regulation of fluid and electrolyte secretion in salivary gland acinar cells. Annu Rev Physiol 67:445-469.

Miledi R and Parker I (1984) Chloride current induced by injection of calcium into Xenopus oocytes. J Physiol 357:173-183.

Mizuta K, Tsutsumi S, Inoue H, Sakamoto Y, Miyatake K, Miyawaki K, Noji S, Kamata N, and Itakura M (2007) Molecular characterization of GDD1/TMEM16E, the gene product responsible for autosomal dominant gnathodiaphyseal dysplasia. Biochem Biophys Res Commun 357:126-132.

Morris AP, Cunningham SA, Benos DJ, and Frizzell RA (1992) Cellular differentiation is required for cAMP but not $\mathrm{Ca}^{2+}$-dependent $\mathrm{Cl}^{-}$secretion in colonic epithelial cells expressing high levels of cystic fibrosis transmembrane conductance regulator. J Biol Chem 267:5575-5583.
Nakanishi A, Morita S, Iwashita H, Sagiya Y, Ashida Y, Shirafuji H, Fujisawa Y, Nishimura O, and Fujino M (2001) Role of gob-5 in mucus overproduction and airway hyperresponsiveness in asthma. Proc Natl Acad Sci USA 98:5175-5180.

Namkung W, Phuan PW, and Verkman AS (2011) TMEM16A inhibitors reveal TMEM16A as a minor component of calcium-activated chloride channel conductance in airway and intestinal epithelial cells. J Biol Chem 286:2365-2374.

Namkung W, Thiagarajah JR, Phuan PW, and Verkman AS (2010) Inhibition of $\mathrm{Ca}^{2+}$-activated $\mathrm{Cl}^{-}$channels by gallotannins as a possible molecular basis for health benefits of red wine and green tea. Faseb $J$ 24:4178-4186.

Nilius B, Prenen J, Szücs G, Wei L, Tanzi F, Voets T, and Droogmans G (1997) Calcium-activated chloride channels in bovine pulmonary artery endothelial cells. J Physiol 498:381-396.

Otowa T, Tanii H, Sugaya N, Yoshida E, Inoue K, Yasuda S, Shimada T, Kawamura Y, Tochigi M, Minato T, et al. (2010) Replication of a genome-wide association study of panic disorder in a Japanese population. J Hum Genet 55:91-96.

Otowa T, Yoshida E, Sugaya N, Yasuda S, Nishimura Y, Inoue K, Tochigi M, Umekage T, Miyagawa T, Nishida N, et al. (2009) Genome-wide association study of panic disorder in the Japanese population. J Hum Genet 54:122-126.

Pacaud P, Loirand G, Mironneau C, and Mironneau J (1989) Noradrenaline activates a calcium-activated chloride conductance and increases the voltage-dependent calcium current in cultured single cells of rat portal vein. Br J Pharmacol 97:139146.

Park MK, Lomax RB, Tepikin AV, and Petersen OH (2001) Local uncaging of caged $\mathrm{Ca}^{2+}$ reveals distribution of $\mathrm{Ca}^{2+}$-activated $\mathrm{Cl}(-)$ channels in pancreatic acinar cells. Proc Natl Acad Sci USA 98:10948-10953.

Parsons SP and Sanders KM (2008) An outwardly rectifying and deactivating chloride channel expressed by interstitial cells of cajal from the murine small intestine. J Membr Biol 221:123-132.

Patel AC, Brett TJ, and Holtzman MJ (2009) The role of CLCA proteins in inflammatory airway disease. Annu Rev Physiol 71:425-449.

Patel S, Joseph SK, and Thomas AP (1999) Molecular properties of inositol 1,4,5trisphosphate receptors. Cell Calcium 25:247-264.

Pauli BU, Abdel-Ghany M, Cheng HC, Gruber AD, Archibald HA, and Elble RC (2000) Molecular characteristics and functional diversity of CLCA family members. Clin Exp Pharmacol Physiol 27:901-905.

Pawłowski K, Lepistö M, Meinander N, Sivars U, Varga M, and Wieslander E (2006) Novel conserved hydrolase domain in the CLCA family of alleged calciumactivated chloride channels. Proteins 63:424-439.

Petrukhin K, Koisti MJ, Bakall B, Li W, Xie G, Marknell T, Sandgren O, Forsman K, Holmgren G, Andreasson S, et al. (1998) Identification of the gene responsible for Best macular dystrophy. Nat Genet 19:241-247.

Pifferi S, Dibattista M, and Menini A (2009a) TMEM16B induces chloride currents activated by calcium in mammalian cells. Pflugers Arch 458:1023-1038.

Pifferi S, Dibattista M, Sagheddu C, Boccaccio A, Al Qteishat A, Ghirardi F, Tirindelli R, and Menini A (2009b) Calcium-activated chloride currents in olfactory sensory neurons from mice lacking bestrophin-2. J Physiol 587:4265-4279.

Piper AS and Large WA (2003) Multiple conductance states of single $\mathrm{Ca}^{2+}$-activated $\mathrm{Cl}^{-}$channels in rabbit pulmonary artery smooth muscle cells. J Physiol 547:181196.

Planells-Cases R and Jentsch TJ (2009) Chloride channelopathies. Biochim Biophys Acta 1792:173-189.

$\mathrm{Qu} \mathrm{Z}$, Fischmeister R, and Hartzell C (2004) Mouse bestrophin-2 is a bona fide Cl(-) channel: identification of a residue important in anion binding and conduction. $J$ Gen Physiol 123:327-340.

$\mathrm{Qu} \mathrm{Z}$ and Hartzell HC (2000) Anion permeation in $\mathrm{Ca}^{2+}$-activated $\mathrm{Cl}(-)$ channels J Gen Physiol 116:825-844.

$\mathrm{Qu} \mathrm{Z}$, Wei RW, and Hartzell HC (2003) Characterization of $\mathrm{Ca}^{2+}$-activated $\mathrm{Cl}^{-}$ currents in mouse kidney inner medullary collecting duct cells. Am J Physiol Renal Physiol 285:F326-F335.

Rasche S, Toetter B, Adler J, Tschapek A, Doerner JF, Kurtenbach S, Hatt H, Meyer H, Warscheid B, and Neuhaus EM (2010) Tmem 16 b is specifically expressed in the cilia of olfactory sensory neurons. Chem Senses 35:239-245.

Rock JR, Futtner CR, and Harfe BD (2008) The transmembrane protein TMEM16A is required for normal development of the murine trachea. Dev Biol 321:141-149. Rock JR, O'Neal WK, Gabriel SE, Randell SH, Harfe BD, Boucher RC, and Grubb BR (2009) Transmembrane protein 16A (TMEM16A) is a $\mathrm{Ca}^{2+}$-regulated $\mathrm{Cl}^{-}$secretory channel in mouse airways. J Biol Chem 284:14875-14880.

Romanenko VG, Catalán MA, Brown DA, Putzier I, Hartzell HC, Marmorstein AD, Gonzalez-Begne M, Rock JR, Harfe BD, and Melvin JE (2010) Tmem16A encodes the $\mathrm{Ca}^{2+}$-activated $\mathrm{Cl}^{-}$channel in mouse submandibular salivary gland acinar cells. J Biol Chem 285:12990-13001.

Rumessen JJ and Thuneberg L (1996) Pacemaker cells in the gastrointestinal tract: interstitial cells of Cajal. Scand J Gastroenterol Suppl 216:82-94.

Sagheddu C, Boccaccio A, Dibattista M, Montani G, Tirindelli R, and Menini A (2010) Calcium concentration jumps reveal dynamic ion selectivity of calcium-activated chloride currents in mouse olfactory sensory neurons and TMEM16b-transfected HEK 293T cells. J Physiol 588:4189-4204.

Saleh SN and Greenwood IA (2005) Activation of chloride currents in murine portal vein smooth muscle cells by membrane depolarization involves intracellular calcium release. Am J Physiol Cell Physiol 288:C122-C131.

Sánchez-Vives MV and Gallego R (1994) Calcium-dependent chloride current induced by axotomy in rat sympathetic neurons. J Physiol 475:391-400.

Sanders KM, Koh SD, and Ward SM (2006) Interstitial cells of cajal as pacemakers in the gastrointestinal tract. Annu Rev Physiol 68:307-343.

Schlichter LC and Elinson RP (1981) Electrical responses of immature and mature Rana pipiens oocytes to sperm and other activating stimuli. Dev Biol 83:33-41.

Schneppenheim R, Castaman G, Federici AB, Kreuz W, Marschalek R, Oldenburg J, Oyen F, and Budde U (2007) A common 253-kb deletion involving VWF and TMEM16B in German and Italian patients with severe von Willebrand disease type 3. J Thromb Haemost 5:722-728. 
Schreiber M and Salkoff L (1997) A novel calcium-sensing domain in the BK channel. Biophys J 73:1355-1363.

Schroeder BC, Cheng T, Jan YN, and Jan LY (2008) Expression cloning of TMEM16A as a calcium-activated chloride channel subunit. Cell 134:1019-1029. Sergeant GP, Hollywood MA, McHale NG, and Thornbury KD (2001) Spontaneous $\mathrm{Ca}^{2+}$ activated $\mathrm{Cl}^{-}$currents in isolated urethral smooth muscle cells. J Urol 166:1161-1166.

Sheridan JT, Worthington EN, Yu K, Gabriel SE, Hartzell HC, and Tarran R (2011) Characterization of the oligomeric structure of the $\mathrm{Ca}^{2+}$-activated $\mathrm{Cl}^{-}$channel Ano1/TMEM16A. J Biol Chem 286:1381-1388.

Smith PM and Gallacher DV (1992) Acetylcholine- and caffeine-evoked repetitive transient $\mathrm{Ca}^{2+}$-activated $\mathrm{K}^{+}$and $\mathrm{Cl}^{-}$currents in mouse submandibular cells. J Physiol 449:109-120.

Sones WR, Davis AJ, Leblanc N, and Greenwood IA (2010) Cholesterol depletion alters amplitude and pharmacology of vascular calcium-activated chloride channels. Cardiovasc Res 87:476-484.

Stephan AB, Shum EY, Hirsh S, Cygnar KD, Reisert J, and Zhao H (2009) ANO2 is the cilial calcium-activated chloride channel that may mediate olfactory amplification. Proc Natl Acad Sci USA 106:11776-11781.

Stöhr H, Heisig JB, Benz PM, Schöberl S, Milenkovic VM, Strauss O, Aartsen WM, Wijnholds J, Weber BH, and Schulz HL (2009) TMEM16B, a novel protein with calcium-dependent chloride channel activity, associates with a presynaptic protein complex in photoreceptor terminals. J Neurosci 29:6809-6818.

Sun H, Tsunenari T, Yau KW, and Nathans J (2002) The vitelliform macular dystrophy protein defines a new family of chloride channels. Proc Natl Acad Sci USA 99:4008-4013.

Suzuki J, Umeda M, Sims PJ, and Nagata S (2010) Calcium-dependent phospholipid scrambling by TMEM16F. Nature 468:834-838.

Tarran R, Loewen ME, Paradiso AM, Olsen JC, Gray MA, Argent BE, Boucher RC and Gabriel SE (2002) Regulation of murine airway surface liquid volume by CFTR and $\mathrm{Ca}^{2+}$-activated $\mathrm{Cl}^{-}$conductances. J Gen Physiol 120:407-418.

Thévenod F (2002) Ion channels in secretory granules of the pancreas and their role in exocytosis and release of secretory proteins. Am J Physiol Cell Physiol 283: C651-C672.

Tian Y, Kongsuphol P, Hug M, Ousingsawat J, Witzgall R, Schreiber R, and Kunzelmann K (2011) Calmodulin-dependent activation of the epithelial calciumdependent chloride channel TMEM16A. Faseb $J$ 25:1058-1068.

Toda M, Tulic MK, Levitt RC, and Hamid Q (2002) A calcium-activated chloride channel (HCLCA1) is strongly related to IL-9 expression and mucus production in bronchial epithelium of patients with asthma. J Allergy Clin Immunol 109:246250.

Tsunenari T, Nathans J, and Yau KW (2006) $\mathrm{Ca}^{2+}$-activated $\mathrm{Cl}^{-}$current from human bestrophin-4 in excised membrane patches. J Gen Physiol 127:749-754.

Tsunenari T, Sun H, Williams J, Cahill H, Smallwood P, Yau KW, and Nathans J (2003) Structure-function analysis of the bestrophin family of anion channels. J Biol Chem 278:41114-41125.

Tsutsumi S, Inoue H, Sakamoto Y, Mizuta K, Kamata N, and Itakura M (2005) Molecular cloning and characterization of the murine gnathodiaphyseal dysplasia gene GDD1. Biochem Biophys Res Commun 331:1099-1106.

Tsutsumi S, Kamata N, Vokes TJ, Maruoka Y, Nakakuki K, Enomoto S, Omura K Amagasa T, Nagayama M, Saito-Ohara F, et al. (2004) The novel gene encoding a putative transmembrane protein is mutated in gnathodiaphyseal dysplasia (GDD). Am J Hum Genet 74:1255-1261.
Vermeer S, Hoischen A, Meijer RP, Gilissen C, Neveling K, Wieskamp N, de Brouwer A, Koenig M, Anheim M, Assoum M, et al (2010) Targeted next-generation sequencing of a $12.5 \mathrm{Mb}$ homozygous region reveals ANO10 mutations in patients with autosomal-recessive cerebellar ataxia. Am J Hum Genet 87:813-819.

von der Weid PY, Rahman M, Imtiaz MS, and van Helden DF (2008) Spontaneous transient depolarizations in lymphatic vessels of the guinea pig mesentery: pharmacology and implication for spontaneous contractility. Am J Physiol Heart Circ Physiol 295:H1989-H2000

West RB, Corless CL, Chen X, Rubin BP, Subramanian S, Montgomery K, Zhu S, Ball CA, Nielsen TO, Patel R, et al. (2004) The novel marker, DOG1, is expressed ubiquitously in gastrointestinal stromal tumors irrespective of KIT or PDGFRA mutation status. Am J Pathol 165:107-113.

Whelan S, de Bakker PI, and Goldman N (2003) Pandit: a database of protein and associated nucleotide domains with inferred trees. Bioinformatics 19:1556-1563.

Winpenny JP, Harris A, Hollingsworth MA, Argent BE, and Gray MA (1998) Calcium-activated chloride conductance in a pancreatic adenocarcinoma cell line of ductal origin (HPAF) and in freshly isolated human pancreatic duct cells. Pflugers Arch 435:796-803.

Xia XM, Fakler B, Rivard A, Wayman G, Johnson-Pais T, Keen JE, Ishii T, Hirschberg B, Bond CT, Lutsenko S, et al. (1998) Mechanism of calcium gating in small-conductance calcium-activated potassium channels. Nature 395:503-507.

Xiao Q, Yu K, Perez-Cornejo P, Cui Y, Arreola J, and Hartzell HC (2011) Voltageand calcium-dependent gating of TMEM16A/Ano1 chloride channels are physically coupled by the first intracellular loop. Proc Natl Acad Sci USA 108:8891-8896.

Yang C and Delay RJ (2010) Calcium-activated chloride current amplifies the response to urine in mouse vomeronasal sensory neurons. J Gen Physiol 135:3-13.

Yang YD, Cho H, Koo JY, Tak MH, Cho Y, Shim WS, Park SP, Lee J, Lee B, Kim BM, et al. (2008) TMEM16A confers receptor-activated calcium-dependent chloride conductance. Nature 455:1210-1215.

Yu K, Lujan R, Marmorstein A, Gabriel S, and Hartzell HC (2010) Bestrophin-2 mediates bicarbonate transport by goblet cells in mouse colon. $J$ Clin Invest 120:1722-1735.

Zeng W, Lee MG, and Muallem S (1997) Membrane-specific regulation of $\mathrm{Cl}^{-}$ channels by purinergic receptors in rat submandibular gland acinar and duct cells. $J$ Biol Chem 272:32956-32965.

Zhang AL and Roomans GM (1999) Multiple intracellular pathways for regulation of chloride secretion in cultured pig tracheal submucosal gland cells. Eur Respir $J$ 13:571-576.

Zhang Y, Stanton JB, Wu J, Yu K, Hartzell HC, Peachey NS, Marmorstein LY, and Marmorstein $\mathrm{AD}$ (2010) Suppression of $\mathrm{Ca}^{2+}$ signaling in a mouse model of Best disease. Hum Mol Genet 19:1108-1118.

Zhou Y, Dong Q, Louahed J, Dragwa C, Savio D, Huang M, Weiss C, Tomer Y, McLane MP, Nicolaides NC, et al. (2001) Characterization of a calcium-activated chloride channel as a shared target of Th2 cytokine pathways and its potential involvement in asthma. Am J Respir Cell Mol Biol 25:486-491.

Zhu MH, Kim TW, Ro S, Yan W, Ward SM, Koh SD, and Sanders KM (2009) A $\mathrm{Ca}^{2+}$-activated $\mathrm{Cl}^{-}$conductance in interstitial cells of Cajal linked to slow wave currents and pacemaker activity. J Physiol 587:4905-4918.

ZhuGe R, Sims SM, Tuft RA, Fogarty KE, and Walsh JV Jr (1998) $\mathrm{Ca}^{2+}$ sparks activate $\mathrm{K}^{+}$and $\mathrm{Cl}^{-}$channels, resulting in spontaneous transient currents in guinea-pig tracheal myocytes. J Physiol 513:711-718. 